\title{
Relationship between pressure drop and heat transfer of developing and fully developed flow in smooth horizontal circular tubes in the laminar, transitional, quasi-turbulent and turbulent flow regimes
}

\author{
M. Everts and J. P. Meyer* \\ *Author for correspondence \\ Department of Mechanical and Aeronautical Engineering, University of Pretoria, Pretoria, 0002, \\ South Africa, E-mail: josua.meyer@up.ac.za
}

\section{Highlights}

- The flow regime boundaries were the same for heat transfer and pressure drop.

- Friction factor correlations for developing and fully developed flow.

- Average Nusselt number correlations for developing and fully developed flow.

\begin{abstract}
Limited work has been done specifically focussing on the relationship between pressure drop and heat transfer in the transitional flow regime. The purpose of this study was therefore to experimentally investigate and compare the pressure drop and heat transfer characteristics of developing and fully developed flow in smooth horizontal circular tubes in the laminar, transitional, quasi-turbulent and turbulent flow regimes. An experimental set-up was designed, built and validated against data from literature. A smooth circular test section with an inner diameter of $11.5 \mathrm{~mm}$, and maximum length-to-diameter ratio of 872, was used. Pressure drop and heat transfer measurements were taken at Reynolds numbers between 500 and 10000 at different heat fluxes. Water was used as the test fluid and the Prandtl number ranged between 3 and 7. A total of 364 mass flow rate measurements, 36809 temperature measurements and 2583 pressure drop measurements were taken. Pressure drop and heat transfer measurements were taken simultaneously and the relationship between pressure drop and heat transfer was determined. It was found that the Reynolds numbers at which transition started and ended was the same for the pressure drop and heat transfer results. Correlations were developed to determine the relationship between heat transfer and pressure drop, as well as the average Nusselt numbers, in the laminar, transitional, quasi-turbulent and turbulent flow regimes, for both developing and fully developed flow in mixed convection conditions. It was found that the relationship between heat transfer and pressure drop can be used as an additional criterion to distinguish the different flow regimes.
\end{abstract}




\section{Graphical abstract}

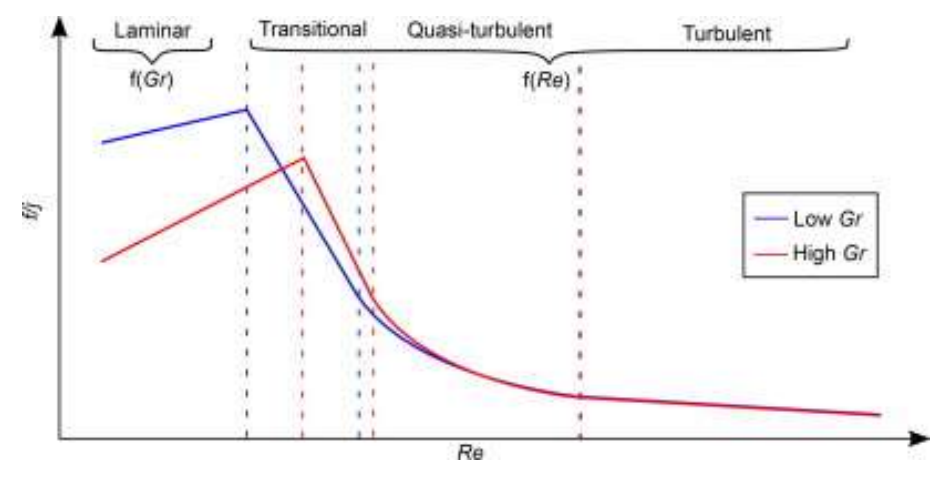

Keywords: Developing flow; transitional flow; quasi-turbulent flow; heat transfer; pressure drop; constant heat flux; mixed convection

\section{Nomenclature}

A Area

$C \quad$ Coefficient used in correlations

$C_{p} \quad$ Constant-pressure specific heat

$D \quad$ Inner diameter

$D_{o} \quad$ Outer diameter

$E B \quad$ Energy balance

$f \quad$ Friction factor

$f_{c r} \quad$ Friction factor at $R e_{c r}$

$f_{q t} \quad$ Friction factor at $R e_{q t}$

$g \quad$ Gravitational acceleration

Gr Grashof number

$G r^{*} \quad$ Modified Grashof number

$G z \quad$ Graetz number

$h \quad$ Heat transfer coefficient

I Current

$j \quad$ Colburn $j$-factor

$k \quad$ Thermal conductivity

$L \quad$ Length

Lt Thermal entrance length

$M \quad$ Measurement or calculated value

$\dot{m} \quad$ Mass flow rate

$\mathrm{Nu} \quad$ Nusselt number

$P \quad$ Pressure

$\mathrm{Pr} \quad$ Prandtl number

$\dot{Q}_{e} \quad$ Electrical input rate

$\dot{Q}_{w} \quad$ Water heat transfer rate

$\dot{q} \quad$ Heat flux

$R_{\text {tube }}$ Thermal resistance

$R e \quad$ Reynolds number

$R e^{\prime} \quad$ Transitional flow inflection point

$R e_{c r} \quad$ Critical Reynolds number

$R e_{q t} \quad$ Start of quasi-turbulent flow regime
$R e_{t} \quad$ Start of turbulent flow regime

$\Delta R e \quad$ Width of transitional flow regime

$T \quad$ Temperature

$T G_{f}$ Transition gradient in terms of friction factor results

$T G_{j}$ Transition gradient in terms of Colburn $j$-factor results

$V \quad$ Velocity/voltage

$x \quad$ Distance from inlet

Greek letters

$\beta \quad$ Thermal expansion coefficient

$\varepsilon \quad$ Surface roughness

$\mu \quad$ Dynamic viscosity

$v \quad$ Kinematic viscosity

$\rho \quad$ Density

Subscripts

$b \quad$ Bulk

c Cross-section

cor Correlation

exp Experimental

$i \quad$ Inlet

L Laminar

$M C D$ Mixed Convection Developing region [1]

$o \quad$ Outer/outlet

$Q T \quad$ Quasi-turbulent

$s \quad$ Surface

$T \quad$ Turbulent

$T G \quad$ Transition gradient 


\section{Introduction}

Heat exchangers have a wide range of industrial and domestic applications, for example boilers in power plants and air-conditioners in cars and buildings. To ensure efficiency, engineers need accurate correlations to optimise the design of these heat exchangers. As the pressure drop is related to pumping power and thus operational running cost, the aim is to obtain high heat transfer coefficients and low pressure drops. In the design process, a selection can be made between a flow regime that is either laminar (low heat transfer coefficients and pressure drops) or turbulent (high heat transfer coefficients and pressure drops). Although pressure drop and heat transfer are usually investigated independently, there exist a direct relationship that is often overlooked [2].

It is important to investigate the relationship between pressure drop and heat transfer, especially in the transitional flow regime, since there exists a fundamental gap in the literature on this subject field. This will be the first step before similar relationships can be developed for more complex geometries. Specifically, for complex geometries it will be much easier for product developers to obtain either the heat transfer coefficients, or pressure drops, as it saves time and money. It is thus desirable to know this relationship since, since it will make it possible to calculate either the heat transfer coefficients or the friction factors, when the other variable is available. Furthermore, it will also give additional insight during the design process regarding the trade-off between high heat transfer coefficients and low pressure drops.

Two analogies were developed, based on the similarity between momentum and heat transfer in the boundary layer [3]: the Reynolds number analogy was developed for Prandtl numbers of unity, while the Chilton-Colburn analogy was developed for laminar and turbulent flow over flat plates for Prandtl numbers between 0.6 and 60. Obot and Esen [4] developed explicit relationships between pressure drop and heat transfer in the laminar flow regime, and noted that the critical Reynolds number was the same for both the pressure drop and heat transfer results. The relationship between pressure drop and heat transfer in the turbulent flow regime, for Reynolds numbers greater than 10 000, was investigated by Allen and Eckert [5]. Gill [6] proposed correlations for the laminar and turbulent flow regimes in a technical note, however, the ranges of the parameters used in the correlations were not given.

Tam et al. [7] investigated pressure drop and heat transfer simultaneously in the transitional flow regime, and found that the transitional flow regime of the pressure drop and heat transfer results were different. The heat transfer transitional Reynolds number range was found to be significantly wider than for pressure drop. However, no correlations were 
developed to quantitively describe the relationship between heat transfer and pressure drop. Olivier and Meyer [8] also investigated pressure drop and heat transfer simultaneously in the laminar, transitional and turbulent flow regimes, and found that the Colburn $j$-factors and friction factors collapsed onto a single graph once the Colburn $j$-factors were multiplied by $4 \mathrm{Pr}^{2 / 3}$. However, from close inspection it follows that although this relationship was valid for the laminar and turbulent flow regimes, the Colburn $j$-factors and friction factors in the transitional flow regime did not collapse onto a single graph. Furthermore, this was for cooling in a tube with a constant surface temperature boundary condition, and no specific attention was given to the start and end of the transitional flow regime.

Although most heat exchangers operate in the turbulent flow regime, the best compromise between high heat transfer coefficients and low pressure drops might be in the transitional flow regime, between laminar and turbulent flow [9]. However, designers are usually advised to avoid this flow regime [10], since the flow is believed to be unstable and chaotic, and little design information is available [9]. According to a recent review paper by Meyer [9], the transitional flow regime has been mainly investigated by Professor Ghajar from Oklahoma State University and his co-workers and by Professor Meyer from the University of Pretoria and his co-workers.

Ghajar and co-workers used local temperature and pressure measurements along a tube length to investigate the effect of different inlet geometries and heating on the heat transfer coefficients and friction factors [7, 11-19]. Although temperature measurements were taken at 31 stations along the test section, the heat transfer investigations mainly focused on the fully developed flow results at $x / D=192$ (station 22). The pressure drop investigations also focussed on the fully developed friction factors, except for Tam et al. [18] who investigated the isothermal and diabatic friction factors of developing and fully developed flow. A constant heat flux boundary condition and different mixtures of distilled water and ethylene glycol were used, which resulted in very high Prandtl numbers (up to 160). Furthermore, due to the combined effects of the relatively large tube diameter $(15.8 \mathrm{~mm})$, and high Prandtl numbers, the Rayleigh numbers were in the order of $10^{5}$ to $10^{6}$ [14]. The Rayleigh number plays an important role in mixed convection heat transfer, and is not only used in their flow regime map (to determine whether the flow is dominated by forced or mixed convection) [14], but also in their correlations to predict the Nusselt numbers in the laminar and transitional flow regimes [13].

Meyer and co-workers used a constant surface temperature boundary condition and water as the test fluid, which resulted in significantly lower Prandtl numbers (approximately 7). 
Furthermore, the fluid was being cooled and not heated. As they considered the average measurements across a tube length, their data contained both developing (laminar and transitional flow regimes) and fully developed (turbulent flow regime) data [8, 20-22]. Although their data contained developing flow, the focus was on the effect of inlet geometries and enhanced tubes and not on the local heat transfer and pressure drop characteristics along the tube length. Meyer and co-workers also investigated transitional flow in nanofluids [23], micro-channels [24], annular flow [25] and using twisted tape inserts [26].

As mentioned by Tam and Ghajar [10] an understanding of the factors that influence the start and end of the transitional flow regime, as well as an understanding of the heat transfer behaviour in this regime, is required in order to select or develop appropriate heat transfer correlations for transitional flow.

Taler [27] gives a comprehensive overview of the available correlations in the transitional flow regime. The first correlation to predict the overall heat transfer coefficients in the transitional flow regime was proposed by Hausen in 1959, however, many other studies found that their experimental heat transfer data in the transitional flow regime deviated from this equation [28]. Both Gnielinski [29] and Churchill [30] also developed correlations for developing and fully developed flow in the transitional flow regime. However, Tam and Ghajar [10] concluded that Gnielinski's and Churchill's correlations failed to accurately predict mixed convection data, since the effects of free convection superimposed on the main flow were not addressed in their works. Heat transfer correlations in the transitional flow regime were also developed by Ghajar and Tam [13], Yu-ting et al. [31] and Lu et al. [32], however, the Prandtl number ranges were limited to the test fluids that were used (mixtures of ethylene glycol and distilled water [13] and molten salt [31, 32]).

Gnielinski [33] proposed a method to determine the heat transfer coefficients in the transitional flow regime, by applying linear interpolation between laminar flow at a Reynolds number of 2300 and turbulent flow at a Reynolds number of 4000 . However, the usually cited Reynolds number range of approximately 2300 to 10000 is only true for very steady and uniform entry flow with a rounded entrance [10]. The Reynolds number range and heat transfer characteristics in the transitional flow regime are significantly affected by inlet geometry [10] as well as free convection effects [34]. Another limitation of this approach is that the laminar Nusselt number correlation is for developing forced convection flow and therefore produces a Nusselt number of 4.36 for fully developed flow. In most cases this will not be correct as laminar flow are normally dominated by mixed convection [1], especially 
when low Prandtl number fluids, such as water, are used. Although this method was tested using the numerical data of Abraham et al. [35], Gnielinski [33] mentioned that "no experimental data were found which have allowed checking the Nusselt numbers obtained by the calculation procedure outlined above in the region of linear interpolation, i.e., between $1000<R e<4000$ ". The lack of experimental data in the transitional flow regime is most probably the main reason for the limited understanding and little design information that is available for transitional flow.

Taler [27] proposed a new heat transfer correlation of transitional and turbulent flow in tubes. The form of the correlation is such that at a Reynolds number of 2300 (where transition is assumed to start) the Nusselt number changes depending on whether the flow is hydrodynamically fully developed and thermally developing, or simultaneously hydrodynamically and thermally developing. Although this correlation accounted for developing flow, the Reynolds number range and heat transfer characteristics in the transitional flow regime are significantly affected by free convection effects [34], while this correlation is not a function of Grashof number. Therefore, this correlation is suited for forced convection conditions, rather than mixed convection conditions.

From literature it follows that Ghajar and co-workers broke the ground with investigating the effect of inlet geometry and heating on transitional flow, as well as the simultaneous investigation of pressure drop and heat transfer, making it possible for others, such as Meyer and co-workers, to follow. However, the focus of previous studies was on the effect of different inlet geometries, enhanced tubes and different Prandtl number fluids. Up to now, no experimental studies have been specifically devoted to the relationship between the pressure drop and heat transfer characteristics of specifically developing flow in the transitional flow regime. The purpose of this study was to experimentally investigate the local pressure drop and heat transfer characteristics of developing and fully developed flow of low Prandtl number fluids in smooth horizontal tubes at different heat fluxes. Laminar, quasi-turbulent and turbulent flow are also addressed to ensure good alignment with the regimes to the transitional flow regime.

This paper forms part of a bigger study and is complimentary to papers published by Meyer and Everts [1] and Everts and Meyer [34, 36]. Meyer and Everts [1] investigated mixed convection laminar flow, as well as the effect of free convection on the laminarturbulent transition along the tube length. Everts and Meyer [34] investigated the heat transfer characteristics of developing and fully developed flow in the transitional flow regime, while the relationship between heat transfer and pressure drop in all flow regimes is 
investigated and quantified in this paper. The results of this paper, as well as in Meyer and Everts [1] and Everts and Meyer [34, 36], were used to develop the flow regime maps, for not only fully developed flow but also developing flow, presented in Everts and Meyer [36].

\section{Experimental set-up}

The details of the experimental set-up and test sections were discussed in detail in Meyer and Everts [1] and Everts [37], and will only be briefly discussed in this paper. The layout of the experimental set-up is shown in Fig. 1. The experimental set-up consisted of a closedloop system, which circulated water from a storage tank, through the test section and back to the storage tank, using two electronically controlled magnetic gear pumps. As the mass flow rates varied over a wide range, Coriolis mass flow meters with different flow rate capacities were installed in parallel. The mass flow meter that would produce the most accurate mass flow rate measurements was selected during the experiments. Downstream of the mass flow meters, the fluid flowed through the flow-calming section to the test section and mixer, and then back into the storage tank.

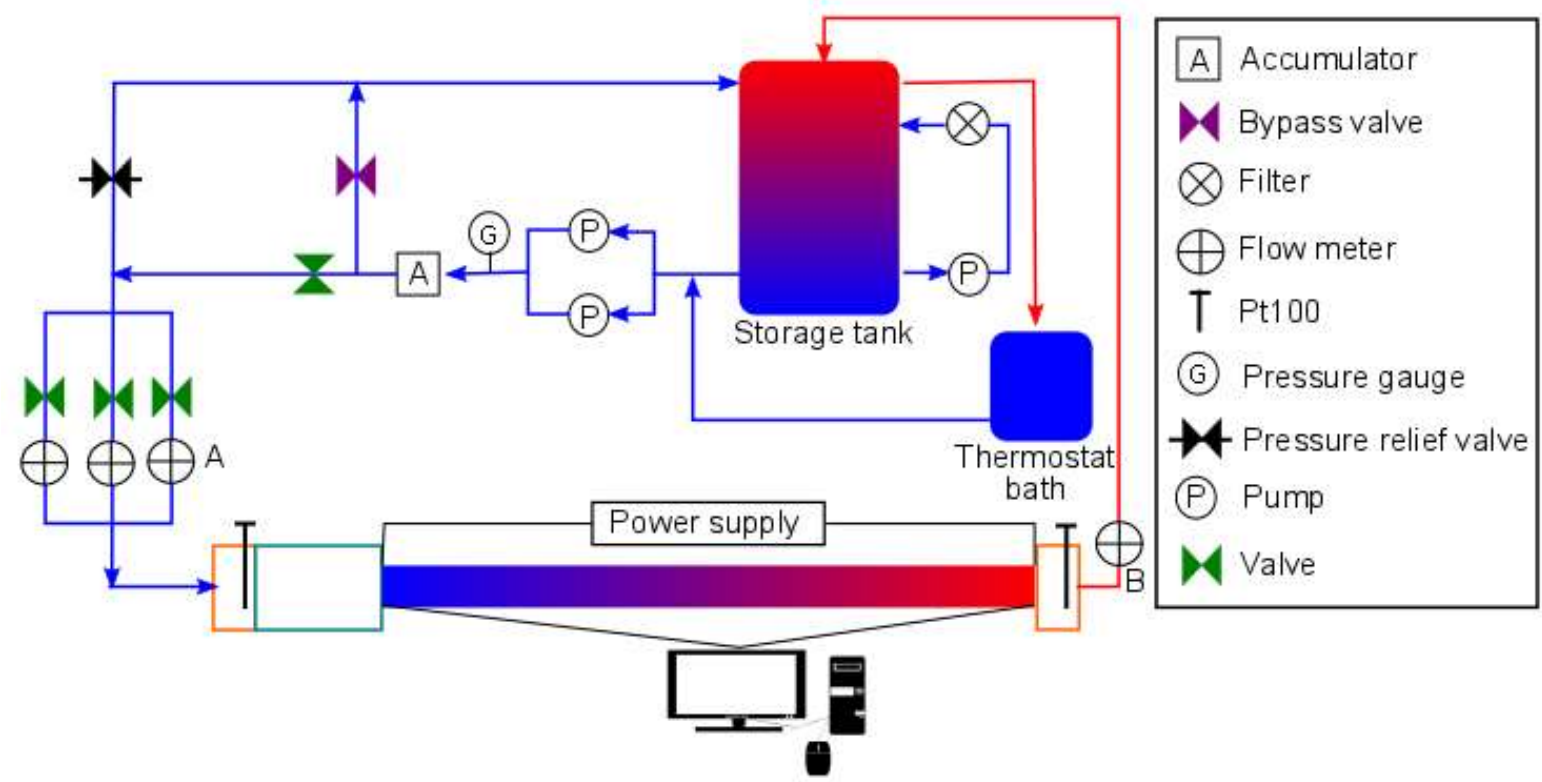

Fig. 1: Schematic representation of experimental set-up used to conduct heat transfer and pressure drop measurements. Water was circulated from the storage tank through the test section and back using two pumps.

\subsection{Flow-calming section}

A flow-calming section, similar to the one used by Ghajar and co-workers [7, 11-18, 38, 39] was installed upstream of the test section to straighten the flow. The only difference was that the fluid first flowed through an additional $100 \mathrm{~mm}$ cavity filled with a soft nylon mesh (to mix the inlet flow to a uniform temperature), before it reached a Pt100 probe, where the average inlet temperature was measured. The acrylic tube had an inner diameter and length 
of $172 \mathrm{~mm}$ and $700 \mathrm{~mm}$, respectively, and an acetal disc was bolted to the inlet section to obtain a square-edged inlet.

\subsection{Test sections}

Two test sections were used in this study and the test sections are shown schematically in Fig. 2, while the details of the thermocouple stations were summarised in Meyer and Everts [1] and Everts [37]. However, as pressure drop measurements were only taken using the $11.5 \mathrm{~mm}$ test section, this test section will be discussed briefly in this paper.

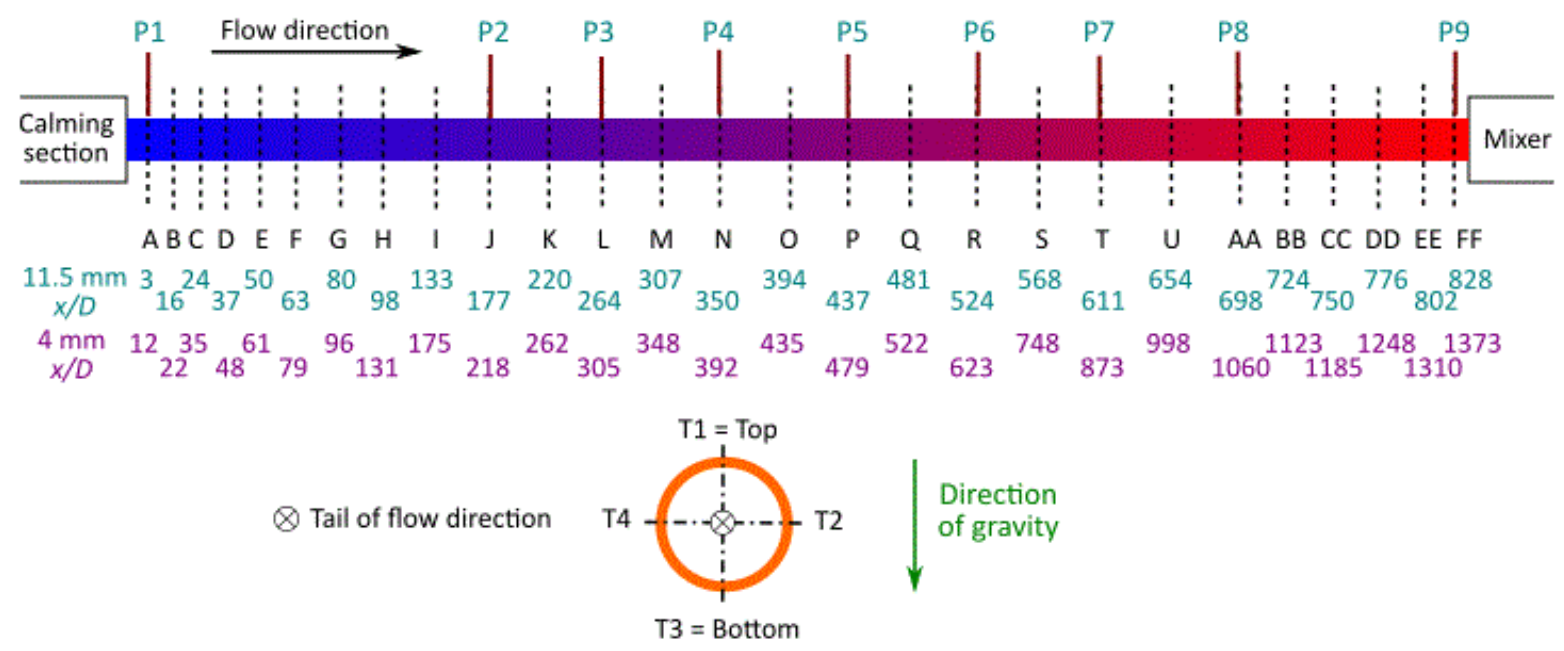

Fig. 2: Schematic representation of the test sections indicating the 27 thermocouples stations, A to FF, on the $11.5 \mathrm{~mm}$ and $4 \mathrm{~mm}$ test sections, as well as the nine pressure taps, P1 to P9, on the $11.5 \mathrm{~mm}$ test section. The $x / D$ values of the thermocouples stations of both test sections, are also given. A cross-sectional view of the test section is included to illustrate the four thermocouple positions spaced around the outside periphery of the tube.

The $11.5 \mathrm{~mm}$ test section was manufactured from a hard-drawn copper tube with an inside diameter of $11.52 \mathrm{~mm}$, outside diameter of $12.7 \mathrm{~mm}$, and a length of $9.81 \mathrm{~m}$. To prevent possible upstream flow effects from influencing the measurements at the last measuring station (station FF), $300 \mathrm{~mm}$ was allowed between the last measuring station (at $x=9.5 \mathrm{~m}$ ) and the mixer (at $x=9.8 \mathrm{~m}$ ).

The average surface roughness $(\varepsilon)$ of the $11.5 \mathrm{~mm}$ copper test section, was measured using a surface roughness tester, to be approximately $0.218 \mu \mathrm{m}$. The relative surface roughness $(\varepsilon / D)$ was thus approximately $1.89 \times 10^{-5}$, and for all practical purposes, the tube can be considered as being smooth. The total length of the $11.5 \mathrm{~mm}$ test section provided maximum length-to-inside diameter ratio $(x / D)$ of 828 , while previous investigations by Ghajar and coworkers [7, 11-13, 15, 16, 18] and Meyer and Olivier [8] had maximum values of 400 and 
350, respectively. The test section was thus more than double the length used in previous studies.

T-type thermocouples with a wire diameter of $0.25 \mathrm{~mm}$ and accuracy of $0.1^{\circ} \mathrm{C}$ were used to measure the surface temperatures at 27 selected axial positions. The thermocouple stations were spaced closer to each other near the inlet of the test section to accurately obtain the temperature profile of developing flow, while the thermocouple stations were spaced further apart on the rest of the test section where the flow was expected to be fully developed. To investigate possible circumferential temperature distributions caused by free convection effects along the tube length, four thermocouples (spaced $90^{\circ}$ apart around the periphery) were used at each thermocouple station.

The thermocouples were soldered onto the $11.5 \mathrm{~mm}$ copper test section in a $0.3 \mathrm{~mm}$ indentation. The thermocouples were calibrated in-situ to an accuracy of $0.1{ }^{\circ} \mathrm{C}$, by pumping water from a thermostat-controlled bath through the flow-calming section, test section and mixer, and back into the thermostat-controlled bath. Reference temperatures were obtained using Pt100 probes at the inlet of the flow-calming section, at the outlet of the mixer and in the thermostat-controlled bath. The temperature of the thermostat-controlled bath was varied between $20^{\circ} \mathrm{C}$ and $60^{\circ} \mathrm{C}$.

To investigate the pressure drop characteristic of developing flow, nine pressure taps were fixed to the $11.5 \mathrm{~mm}$ test section by silver soldering $30 \mathrm{~mm}$ long capillary tubes at each pressure tap station (Fig. 2). A $1 \mathrm{~mm}$ diameter hole was then drilled through the capillary tube and the copper tube. This small diameter was chosen to ensure that the pressure taps did not cause flow obstructions in the test section and that the diameter was less than $10 \%$ of the test section's inner diameter [40]. To prevent incorrect pressure drop measurements, care was taken to remove all the burrs from the inside of the test section. A borescope was pulled through the test section to visually inspect and ensure that all the burrs were properly removed. A bush tap with a quick release coupling was inserted over the capillary tubes, and nylon tubing was used to connect the pressure taps to the differential pressure transducers.

The thermal entrance length at a Reynolds number of 2300 and a Prandtl number of 6, was calculated to be $7.95 \mathrm{~m}$ (using $L t=0.05 \operatorname{RePrD}$ [3]). The Prandtl number decreases with increasing temperature, which implies that the thermal entrance length will also decrease as the fluid is being heated. It was therefore assumed that the flow in the last $1.5 \mathrm{~m}$ of the test section will always be fully developed (this was experimentally verified by the local surfacefluid temperature differences). It was further assumed that the pressure drop measurements across the first seven tube lengths $(0 \mathrm{~m}<L<8 \mathrm{~m})$ of the test section may contain developing 
and fully developed flow, depending on the Reynolds number, Prandtl number and heat flux. The pressure drops were measured between the first pressure tap (P1) and the respective pressure tap (P2 to P8), while the pressure drop of the fully developed region was measured between pressure taps $\mathrm{P} 8$ and $\mathrm{P} 9$.

Differential pressure transducers with interchangeable diaphragms were used to measure the pressure drops in the axial direction the test section. DP103 pressure transducers were used to measure the pressure drop across the $1.5 \mathrm{~m}$ and $2 \mathrm{~m}$ lengths since diaphragms with a smaller full-scale (and thus higher accuracy) could be used in these pressure transducers. DP15 pressure transducers were used to measure the pressure drop across the other tube lengths. The accuracy of the diaphragms was $0.25 \%$ of the full-scale, and different diaphragms were used to minimise the uncertainties of the pressure drop measurements. One set of diaphragms were used between Reynolds numbers of 500 and 4000 and another set between Reynolds numbers of 2000 and 10 000. The diaphragms with a full-scale smaller than $2.5 \mathrm{kPa}$ were calibrated using a Betz manometer with an accuracy of $2.5 \mathrm{~Pa}$, while the other diaphragms were calibrated using a low pressure controlled air manometer with an accuracy of $10 \mathrm{~Pa}$.

To obtain a constant heat flux boundary condition, four constantan wires (connected in parallel) with a diameter of $0.38 \mathrm{~mm}$ were coiled around the test section. The test section was thermally insulated with $120 \mathrm{~mm}$ thick Armaflex insulation with a thermal conductivity of $0.034 \mathrm{~W} / \mathrm{m} . \mathrm{K}$. The maximum heat loss was estimated with one-dimensional conduction heat transfer calculations to be less than $3 \%$.

\subsection{Mixer}

During laminar flow measurements, significant cross-sectional temperature gradients in the radial and tangential directions developed throughout the test section. Therefore, to obtain uniform tube outlet temperatures, a mixer was inserted after the test section to mix the water exiting the test section. The purpose of the mixer was twofold: to house the splitter plates, as well as to house a Pt100 probe that was used to measure the average outlet water temperatures. The mixer design was based on work done by Bakker et al. [41], who investigated laminar flow in static mixers with helical splitter plates.

\subsection{Experimental procedure}

Details of the experimental procedure were given in Meyer and Everts [1]. In the laminar flow regime, at very low Reynolds numbers, approximately 30 minutes was required to reach 
steady-state conditions. Although the mass flow rates in the transitional flow regime were greater than in the laminar flow regime, up to 1 hour was required to reach steady-state due to the temperature and mass flow rate fluctuations inside the tube. In the quasi-turbulent and turbulent flow regimes, approximately 15 minutes was required for steady-state. After steady-state had been reached, 200 measuring points (temperature, pressure and mass flow rate) were captured at a frequency of $10 \mathrm{~Hz}$. Due to the large amount of data points, the time required to reach steady-state, as well as the ranges of the pressure transducer diaphragms, the experiments were divided into two categories: experiments were first conducted for laminar and transitional flow between Reynolds numbers of 500 and 4000 , and then for transitional, quasi-turbulent and turbulent flow, between Reynolds numbers of 2000 and 10000.

\section{Data reduction}

As a constant heat flux boundary condition was applied to the test section, the average axial temperature of the water increased linearly. The bulk fluid temperature, $T_{b}$, along a tube length, $L(x)$, measured from the inlet of the test section, was obtained using a linear temperature distribution between the measured inlet, $T_{i}$, and measured outlet, $T_{o}$, temperatures of the fluid over length, $L$ :

$$
T_{b}=\left(\frac{T_{o}-T_{i}}{L}\right) \frac{L(x)}{2}+T_{i}
$$

The properties of water (density, $\rho$, dynamic viscosity, $\mu$, thermal conductivity, $k$, specific heat, $C_{p}$, Prandtl number, $\operatorname{Pr}$, and thermal expansion coefficient, $\beta$ ) were determined using the thermophysical correlations for liquid water [42] at the bulk fluid temperature.

The bulk Reynolds number, $R e$, was calculated as:

$$
R e=\frac{\dot{m} D}{\mu A_{c}}
$$

where $\dot{m}$ was the measured mass flow rate, $D$ was the measured inner-tube diameter, $\mu$ was the dynamic viscosity, and $A_{\mathrm{c}}$ the cross-sectional area of the test section $\left(A_{c}=\pi / 4 D^{2}\right)$.

The electrical input rate $\left(\dot{Q}_{e}=V I\right)$ remained constant, resulting in a constant heat flux. The heat transfer rate to the water, $\dot{Q}_{w}$, was determined from the measured mass flow rate, measured inlet and outlet temperatures of the water and the specific heat which was calculated at the bulk fluid temperature: 


$$
\dot{Q}_{w}=\dot{m} C_{p}\left(T_{o}-T_{i}\right)
$$

The heat transfer rate to the water, $\dot{Q}_{w}$, was continuously monitored by comparing it to the electrical input rate, $\dot{Q}_{e}$, which should ideally be equal since the test section was well insulated. The energy balance, $E B$, which ideally should be as close as possible to zero, was determined as:

$$
E B=\left|\frac{\dot{Q}_{e}-\dot{Q}_{w}}{\dot{Q}_{e}}\right| * 100=\left|\frac{V I-\dot{m} C_{p}\left(T_{o}-T_{i}\right)}{V I}\right| * 100
$$

The average energy balance of all the experiments that were conducted was less than $3 \%$, which was in good agreement with the calculations estimating the heat losses through the insulation material.

The heat flux, $\dot{q}$, on the inside of the tube wall was determined from the heat transfer rate to the water, $\dot{Q}_{w}$, and the inner surface area, $A_{s}$, of the test section along the heated length:

$$
\dot{q}=\frac{\dot{Q}_{w}}{A_{s}}=\frac{\dot{m} C_{p}\left(T_{o}-T_{i}\right)}{\pi D L}
$$

The heat transfer rate to the water was used to determine the heat flux, since it was regarded as more accurate than the electrical input rate. As the energy balance was not zero, and some losses did occur to the ambient air, the electrical input rate was always slightly higher than the heat transfer rate to the water.

The average of the four temperature measurements at a station was used as the average surface temperature, $T_{s}$, at a specific thermocouple station:

$$
T_{S}(x)=\frac{T_{1}+T_{2}+T_{3}+T_{4}}{4}
$$

The thermal resistance across the tube wall, $R_{\text {tube }}$, was calculated using the following equation:

$$
R_{\text {tube }}=\frac{\ln \left(\frac{D_{o}}{D}\right)}{2 \pi k L}
$$

where $D_{o}$ and $D$ were the measured outside and inside diameters of the tube. 
The thermal conductivity of copper is $401 \mathrm{~W} / \mathrm{m} . \mathrm{K}$, therefore the thermal resistance in the $11.5 \mathrm{~mm}$ test section was calculated to be $4.05 \times 10^{-6 \circ} \mathrm{C} / \mathrm{W}$, as the wall thickness was $0.6 \mathrm{~mm}$. Therefore, the temperature difference across the tube wall was approximately $0.004^{\circ} \mathrm{C}$ when the maximum heat input $\left(3 \mathrm{~kW} / \mathrm{m}^{2}\right)$ was applied to the test section. The negligible temperature difference led to the assumption that the temperature on the inside surface of the test section was equal to the temperature measurement on the outside surface of the test section, since the temperatures in general could only be measured to an accuracy of $0.1^{\circ} \mathrm{C}$. It was therefore assumed that the surface temperatures, determined from Eq. (6), was the average surface temperature on the inside of the tube at a measuring station in the $11.5 \mathrm{~mm}$ test section.

The average surface temperature of the test section, $T_{s}$, along tube length $L(x)$, was calculated from the local temperature measurements, using the trapezoidal rule:

$$
T_{s}=\frac{1}{L(x)} \int_{0}^{L(x)} T_{s}(x) d x
$$

The average heat transfer coefficients, $h$, were then determined from the following equation, since the heat flux, $\dot{q}$, surface temperature, $T_{s}$, and bulk fluid temperature, $T_{b}$, were known:

$$
h=\frac{\dot{q}}{\left(T_{s}-T_{b}\right)}
$$

The average Nusselt numbers, $N u$, were determined from the average heat transfer coefficients as follows:

$$
N u=\frac{h D}{k}
$$

The heat transfer results were also investigated in terms of the Colburn $j$-factor, to account for the variation in the Prandtl number:

$$
j=\frac{N u}{\operatorname{RePr}^{\frac{1}{3}}}
$$

The bulk Grashof numbers, $G r$, were determined using the following equation: 


$$
G r=\frac{g \beta\left(T_{s}-T_{b}\right) D^{3}}{v^{2}}
$$

where $9.81 \mathrm{~m} / \mathrm{s}^{2}$ was used for the gravitational acceleration, $g$, and the kinematic viscosity was obtained from the density and dynamic viscosity $(v=\mu / \rho)$.

The bulk modified Grashof numbers, $G r^{*}$, which are a function of heat flux instead of temperature difference, were the product of the bulk Grashof numbers and average Nusselt numbers:

$$
G r^{*}=G r N u=\frac{g \beta \rho \dot{q} D^{4}}{v^{2} k}
$$

The average friction factors, $f$, were calculated from the mass flow rate and pressure drop measurements, $\Delta P$, between two pressure taps which was apart from each other a length $L(x)$ :

$$
f=\frac{2 \Delta P D}{L(x) \rho V^{2}}=\frac{\Delta P \rho D^{5} \pi^{2}}{8 \dot{m}^{2} L(x)}
$$

In general, the percentage error of a measurement or calculated value $(M)$ was determined as \%error $=\left|M_{\text {exp }}-M_{\text {cor }}\right| M_{\text {cor }} \times 100$. The average percentage error was taken as the average of the absolute errors of the data points.

The method suggested by Dunn [43] was used to calculate the uncertainties of the parameters obtained in the data reduction. All uncertainties were calculated within a $95 \%$ confidence interval and the uncertainty analysis details are given in Everts [37]. The Reynolds number uncertainties were approximately $1.5 \%$ in the laminar and turbulent flow regimes, and increased to $2 \%$ in the transitional flow regime due to the mass flow rate fluctuations that occurred in this flow regime. The laminar Nusselt number uncertainties were less than $4 \%$, and decreased with increasing heat flux. In the transitional flow regime, the uncertainties increased to approximately $10 \%$ (depending on the heat flux), due to the temperature fluctuations. The Nusselt number uncertainties in the turbulent flow regime increased with increasing Reynolds number and the average Nusselt number uncertainty at a Reynolds number of 6000 was $8 \%$.

The laminar friction factor uncertainties across the tube lengths $0 \mathrm{~m}<L<2 \mathrm{~m}$, $0 \mathrm{~m}<L<3 \mathrm{~m}$ and $8 \mathrm{~m}<L<9.5 \mathrm{~m}$, were higher (average uncertainty of $13 \%$ ) than for the other tube lengths. This was due to the limitations of the pressure transducer diaphragms, since smaller diaphragms were not available. The laminar friction factor uncertainties for the 
other tube lengths were approximately $10 \%$ at the minimum Reynolds number, and decreased to approximately $2 \%$ just before transition started. In the transitional flow regime, the uncertainties increased to approximately $20 \%$ due to the fluctuations inside the test section. The uncertainties in the turbulent flow regime varied between $1 \%$ and $3 \%$.

\section{Test matrix}

Experiments conducted at different mass flow rates and heat fluxes are summarised in Table 1. The test matrix consisted of 364 mass flow rate measurements, 36809 temperature measurements and 2583 pressure drop measurements.

\begin{tabular}{cccccc} 
Table 1: Experimental test matrix. & Reynolds \\
\hline $\begin{array}{c}\text { Test } \\
\text { section }\end{array}$ & $\begin{array}{c}\text { Heat flux } \\
{\left[\mathrm{kW} / \mathrm{m}^{2}\right]}\end{array}$ & $\begin{array}{c}\text { Mass flow rate } \\
\text { number range }\end{array}$ & $\begin{array}{c}\text { Temperature } \\
\text { measurements } \\
\text { measurements* }\end{array}$ & $\begin{array}{c}\text { Pressure drop } \\
\text { measurements }\end{array}$ \\
\hline \multirow{4}{*}{$11.5 \mathrm{~mm}$} & 0 & $507-14968$ & 178 & 16535 & 1095 \\
& 1 & $597-9280$ & 69 & 7521 & 552 \\
& 2 & $894-9376$ & 62 & 6758 & 496 \\
& 3 & $1061-9509$ & 55 & 5995 & 440 \\
\hline
\end{tabular}

*4 thermocouples per station

\section{Validation}

Extensive validation experiments were conducted and the details are given in Everts [37]. The heat transfer validation consisted of local laminar Nusselt number validations for forced and mixed convection conditions, as well as average laminar and turbulent Nusselt number validations. The pressure drop validation consisted of isothermal friction factor validations of developing and fully developed flow in the laminar and turbulent flow regimes.

It was very challenging to obtain forced convection conditions in macro tubes. The average fully developed Nusselt number $(50<x / D<827)$ at a Reynolds number of 941 and heat flux of only $60 \mathrm{~W} / \mathrm{m}^{2}$, was found to be 4.75 . This was within $8.9 \%$ of the theoretical value of 4.36 for fully developed forced convection laminar flow. The results also correlated well with the correlation of Shah and London [44], with an average deviation of 19\%, while the deviation between $x / D=567$ and $x / D=724$ was less than $3 \%$. The local laminar Nusselt numbers for mixed convection conditions, were compared to the correlation of Morcos and Bergles [45], which is valid for fully developed flow. The results correlated well with an average deviation of $6 \%$ between $x / D=37$ and $x / D=827$.

The average laminar Nusselt numbers also correlated well with the correlation of Morcos and Bergles [45] with an average deviation of $2 \%$. Furthermore, the average turbulent 
Nusselt numbers correlated very well with the correlations of Ghajar and Tam [13] and Gnielinski [29], with an average deviation of less than $1 \%$ and $5 \%$, respectively.

The isothermal friction factors were validated for both fully developed $(8 \mathrm{~m}<L<9.5 \mathrm{~m})$ and developing $(0 \mathrm{~m}<L<2 \mathrm{~m})$ flow, between Reynolds numbers of 500 and 10000 . Meyer and Everts [1] found that when the flow was simultaneously hydrodynamically and thermally developing, a coefficient of 0.12 should be used instead of 0.05 , which was used to calculate the thermal entrance length $(L t=C \operatorname{RePrD}$ [3]) of this test section. However, average measurements were considered in this study, which makes the results 'less sensitive' for developing flow. Furthermore, from the results of Meyer and Everts [1], it follows that the difference between the local laminar Nusselt numbers at $1 / G z=0.05$ and $1 / G z=0.12$, was only 4.4\%. For this study, the flow can thus be considered as fully developed for $8 \mathrm{~m}<L<9.5 \mathrm{~m}$. The laminar fully developed friction factors correlated well with the Poiseuille flow friction factor of 64/Re [46], with an average deviation of $2.5 \%$ between Reynolds numbers of 500 and 2000 , which confirms that the fully developed flow assumption was correct.

The laminar developing flow friction factors correlated well with the friction factors predicted by the correlation of Tam et al. [7], with an average deviation of $3.3 \%$ between Reynolds numbers of 500 and 2 300. The fully developed turbulent friction factors correlated very well with the correlations of Blasius [46] and Fang et al. [47], with an average deviation of $0.3 \%$ and $1.1 \%$, respectively, between Reynolds numbers of 3000 and 10000 . The turbulent friction factors in the developing section also correlated very well with the correlations of Blasius [46] and Fang et al. [47], with average deviations of $0.35 \%$ and $1.2 \%$, respectively, between Reynolds numbers of 3500 and 10000.

\section{Flow regime nomenclature}

The methodology and nomenclature presented by Everts and Meyer [34], were used to determine the boundaries between the laminar, transitional, quasi-turbulent and turbulent flow regimes. However, they considered heat transfer data (Nusselt numbers and Colburn $j$ factors) only and not pressure drop data. In this paper, specifically the pressure drop data was also used with the direct relationship between heat transfer and pressure drop results. The relationships between the friction factors and Colburn $j$-factors are shown schematically in Fig. 3, and is applied in Section 7.3. In addition to the transitional flow definitions presented by Everts and Meyer [34], the transition gradient for friction factors (which represents 
straight line between the friction factors at the start $\left(R e_{c r}\right)$ and end $\left(R e_{q t}\right)$ of the transitional flow regime), is defined as:

$$
T G_{f}=\frac{f_{q t}-f_{c r}}{R e_{q t}-R e_{c r}}
$$

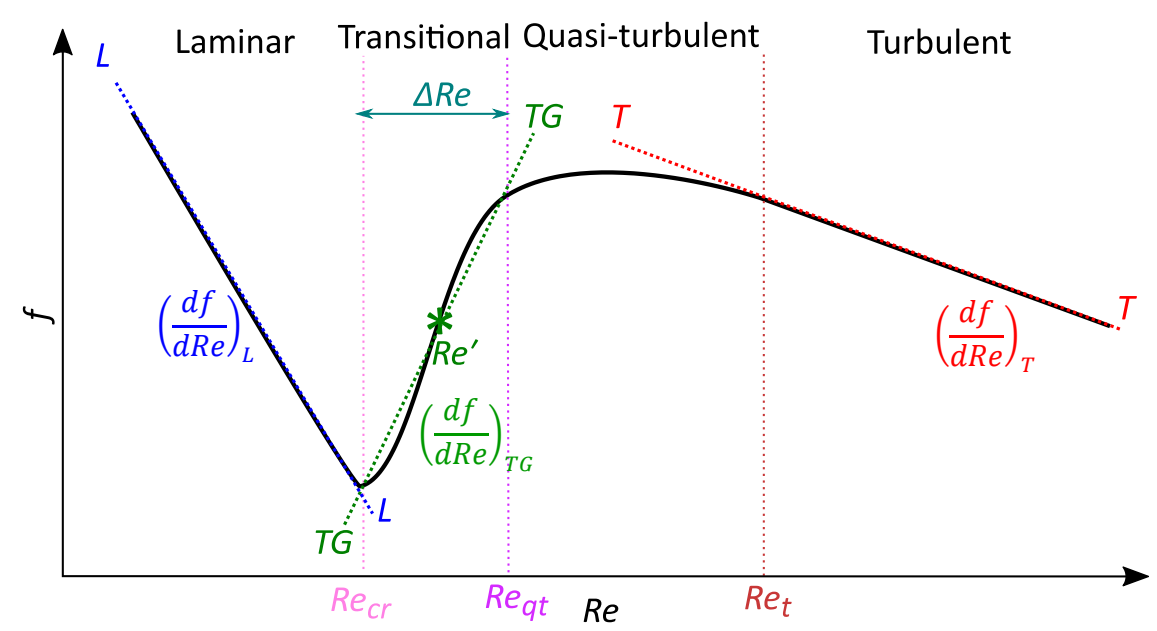

(a)

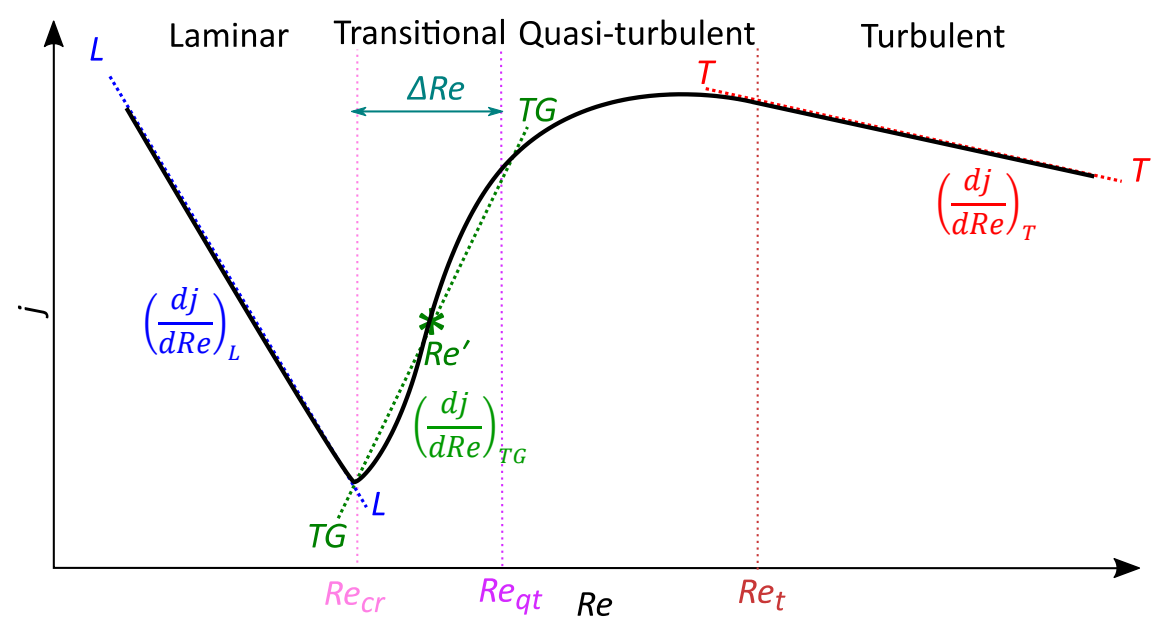

(b)

Fig. 3: Schematic representation of the different flow regimes for forced convection in terms of (a) friction factor and (b) Colburn $j$-factor as a function of Reynolds number.

\section{Results and discussion}

\subsection{Pressure drop}

The isothermal friction factors as a function of Reynolds number for different tube lengths are compared in Fig. 4. For fully developed isothermal flow, the laminar friction factors should be equal to 64/Re [46], which is indicated by the solid blue line. Although the pressure drop increased with increasing fluid velocity, the friction factor was inversely proportional to the velocity squared (Eq. (14)), therefore the friction factor decreased with increasing Reynolds number. 
From this figure it follows that, at a fixed Reynolds number of 2000 , the laminar friction factors decreased and approached the solid blue line, as the tube length increased. The friction factors of developing flow are higher than for fully developed flow, since the maximum wall shear stress is found at the inlet of the test section where the hydrodynamic boundary layer is the thinnest. As the tube length was increased, a larger portion of the tube length contained fully developed flow, therefore the average friction factors decreased and approached the fully developed friction factors. Once the flow was fully developed, for example over the last part of the tube length $(8 \mathrm{~m}<L<9.5 \mathrm{~m})$, the friction factors corresponded very well with $64 / R e$ and the average deviation was $2.5 \%$. This trend was clear for Reynolds numbers larger than 2 000, but challenging to identify for Reynolds numbers less than 1000 , due to the uncertainties of the friction factors that increased with decreasing Reynolds numbers.

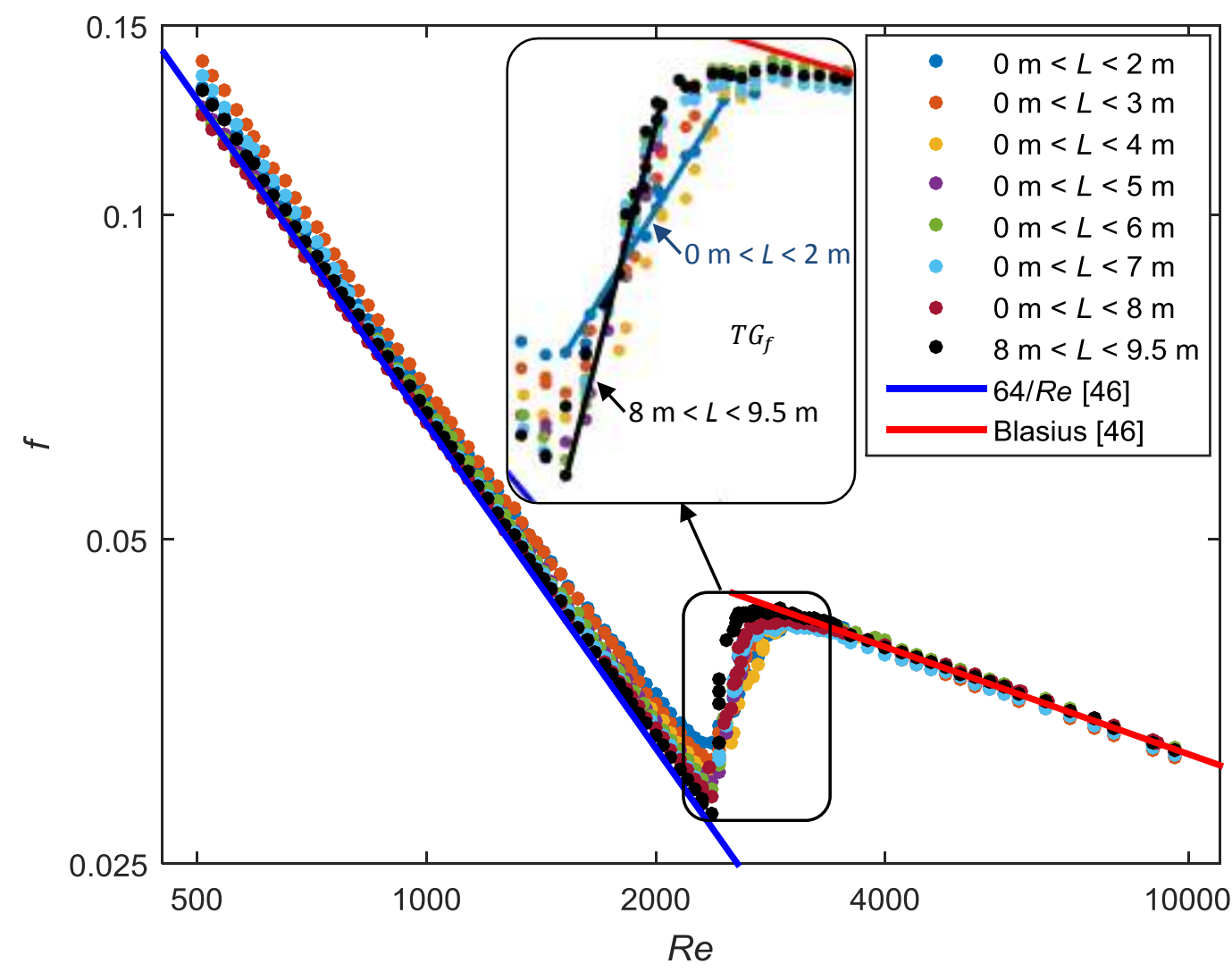

Fig. 4: Comparison of isothermal friction factors as a function of Reynolds number across different tube lengths.

From the detailed view in Fig. 4 it follows that the transition gradient, $T G_{f}$, increased with increasing tube length, thus it increased as the flow approached fully developed flow. The gradient of the first tube length $(0 \mathrm{~m}<L<2 \mathrm{~m})$ over which the pressure drop was measured 
was approximately $1.9 \times 10^{-5}$ and is indicated by the solid blue line. The gradient of the last tube length $(8 \mathrm{~m}<L<9.5 \mathrm{~m})$, that contained fully developed flow only, was approximately $4.6 \times 10^{-5}$, and is indicated by the solid black line. Furthermore, the start of transition was independent of tube length, since transition started at the same Reynolds number of 2361 for all tube lengths. However, the Reynolds number at which transition ended decreased from 2809 for $0 \mathrm{~m}<L<2 \mathrm{~m}$, to 2622 for $8 \mathrm{~m}<L<9.5 \mathrm{~m}$ (fully developed flow).

To investigate the effect of free convection on the friction factors of developing and fully developed flow, the friction factors as a function of Reynolds number at different heat fluxes and tube lengths are compared in Fig. 5. From this figure it follows that as the heat flux was increased, the laminar friction factors increased slightly. This trend became more prominent as the tube length was increased and the flow approached fully developed flow (Fig. 5(h)), since free convection effects increased as the thermal boundary layer thickness increased.

The Reynolds number at which transition started increased with increasing heat flux, however, it was found by Everts and Meyer [34] that this was only due to the decreasing viscosity with increasing temperature, and that free convection effects actually caused transition to occur at lower mass flow rates. Similar to the isothermal results, the transition gradient increased with increasing tube length (flow approached fully developed flow), which caused the width of the transitional flow regime, $\Delta R e$, to decrease. Furthermore, the width of the transitional flow regime also decreased with increasing heat flux. Meyer and Everts [1] found that as free convection effects were increased, by increasing the heat flux and/or tube diameter, the flow transitioned faster from laminar to turbulent along the tube length. This led to a decreased transition region along the test section, and also a decreased transitional flow regime in terms of Reynolds number [34].

From Fig. 5(h) it follows that once the flow was fully developed and free convection effects were significant, the transitional flow regime became negligible, and it seems as if $T G_{f} \rightarrow \infty$ at $R e_{c r}$. However, this was not the case as the changes in the $y$-scale (friction factor) were much smaller than the changes in the $x$-scale (Reynolds number). Although $T G_{f}$ was actually a small value of $4.2 \times 10^{-5}$, it was still 4.6 times greater than for $0 \mathrm{~m}<L<2 \mathrm{~m}$ (Fig. 5(a)). Severe fluctuations occurred inside the test section and after time (up to one hour) the flow stabilised at the critical Reynolds number, and then in the quasi-turbulent flow regime at the next increasing experimental Reynolds number increment. Similar results were obtained by Everts and Meyer [34] when the local heat transfer coefficients of developing and fully developed flow were investigated. 


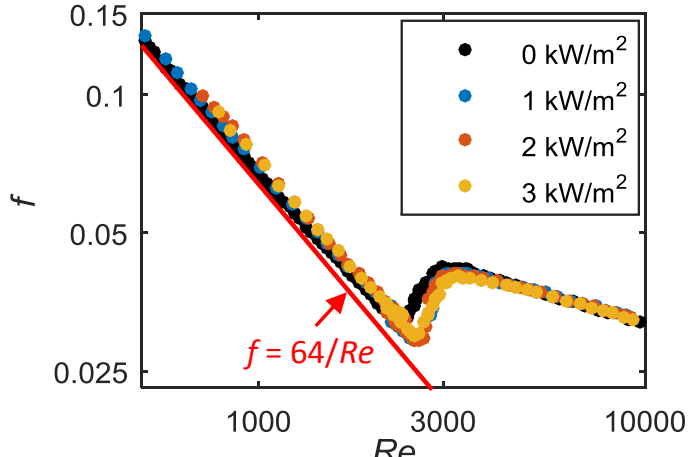

(a)

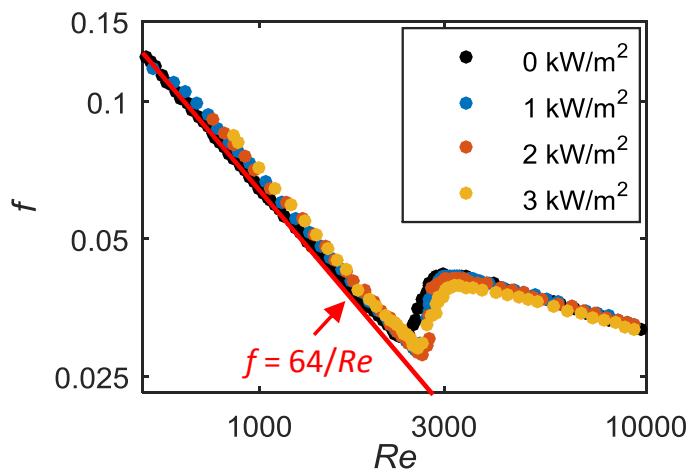

(c)

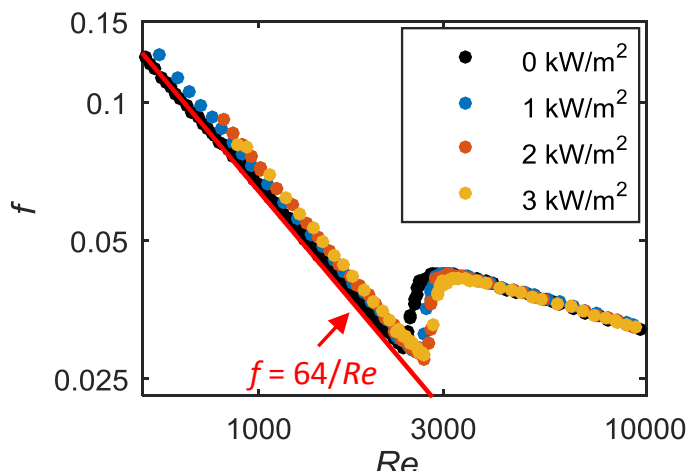

(e)

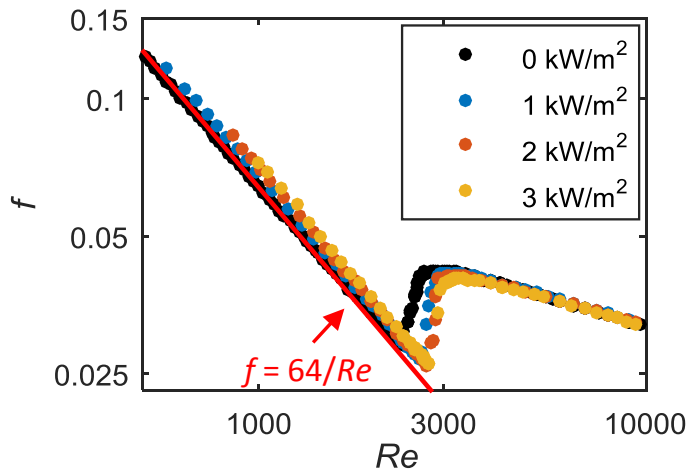

(g)

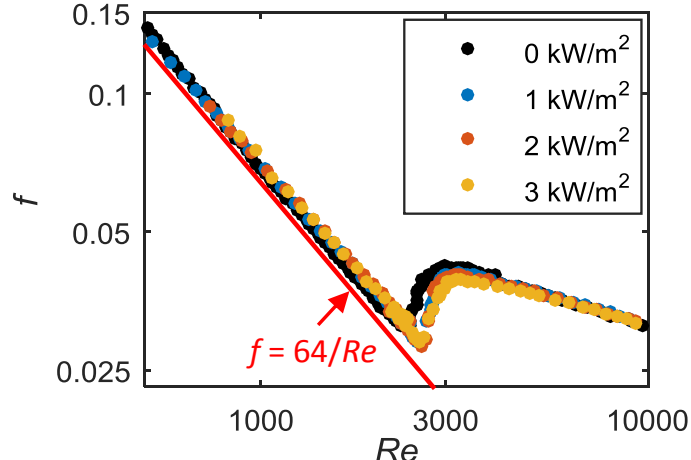

(b)

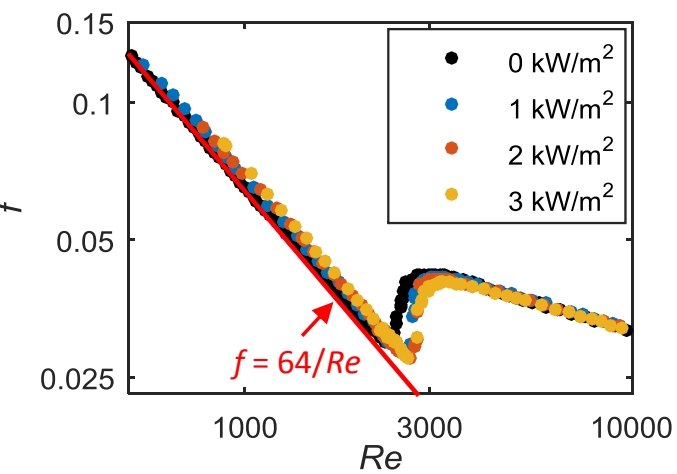

(d)

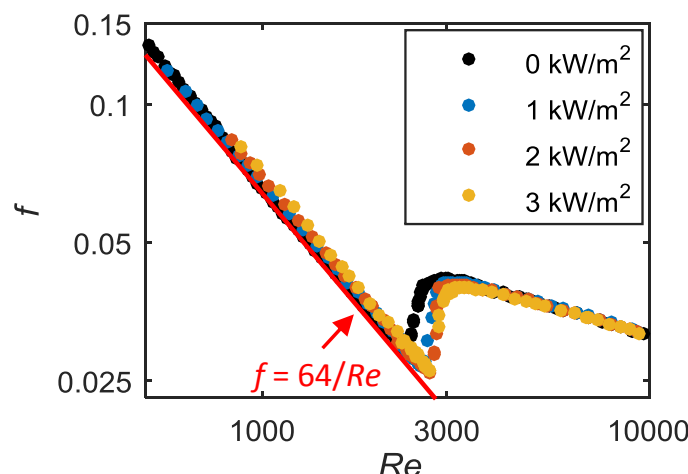

(f)

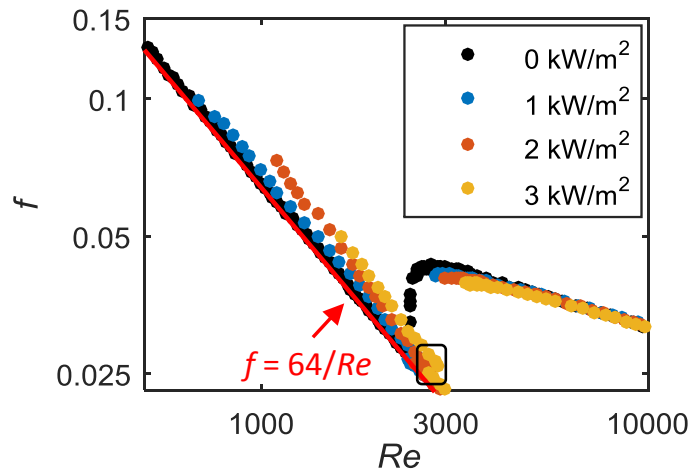

(h)

Fig. 5: Comparison of friction factor as a function of Reynolds number at different heat fluxes across (a) $0 \mathrm{~m} \leq L \leq 2 \mathrm{~m}$, (b) $0 \mathrm{~m} \leq L \leq 3 \mathrm{~m}$, (c) $0 \mathrm{~m} \leq L \leq 4 \mathrm{~m}$, (d) $0 \mathrm{~m} \leq L \leq 5 \mathrm{~m}$, (e) $0 \mathrm{~m} \leq L \leq 6 \mathrm{~m}$, (f) $0 \mathrm{~m} \leq L \leq 7 \mathrm{~m}$, (g) $0 \mathrm{~m} \leq L \leq 8 \mathrm{~m}$, and (h) $8 \mathrm{~m} \leq L \leq 9.5 \mathrm{~m}$. The heat flux of $0 \mathrm{~kW} / \mathrm{m}^{2}$ indicate isothermal flow. The black rectangle in Fig. $5(\mathrm{~h})$ indicates the region where different pressure transducers had to be used because of pressure transducer diaphragm range limitations. 
As expected, there was no significant difference between the results of the different tube lengths and heat fluxes in the quasi-turbulent and turbulent flow regimes, since the flow was fully developed and free convection effect were suppressed by the velocity of the fluid.

From the black rectangle in Fig. 5(h) it follows that a discontinuity existed between Reynolds numbers of 2700 and 2900 . This was due to the different pressure transducers that were used to conduct experiments between Reynolds numbers of 500 and 4 000, and between 2000 and 10000 . At a Reynolds number of 2 880, friction factors of 0.02596 and 0.02368 were obtained using the two different pressure transducers. As this difference was only $1.6 \%$, it was considered to be negligible. Slight discontinuities existed in the friction factors of the other tube lengths as well, however, it was even less due to the longer tube lengths and lower uncertainties.

Similar to Langhaar [48], the friction factor results in Fig. 5 were investigated in terms of the product of the friction factor and Reynolds number $(f R e)$, as a function of the dimensionless axial distance $((x / D) / R e)$ in Fig. 6. For fully developed laminar flow, $f R e$ should be equal to 64, which is indicated by the solid red line. As indicated by the arrows, the different flow regimes can also be identified in Fig. 6.

From the isothermal results (black markers in Fig. 6) it follows that laminar friction factors formed a diagonal line (with a negative gradient) near the inlet of the test section (Fig. 6(a)), but the gradient of this line approached zero as the flow approached fully developed flow (Fig. 6(h)). Although Tam et al. [7] found that heating caused the friction factors to decrease in the laminar and transitional flow regimes, the opposite trend was found in Fig. 5 and Fig. 6. Similar to the results obtained by Tam and Ghajar [15], the laminar friction factors increased with increasing heat flux. This increase became more significant as the tube length increased and the flow approached fully developed flow. Tam and Ghajar [15] explained that the velocity profile changes when mixed convection occurs. As the heat flux was increased, the density decreased, and the shear stress due to the change in the velocity profile increased, which led to increased friction factors. However, the decreasing density and viscosity with increasing temperature may also lead to decreased pressure drops and friction factors, as was found by Tam et al. [7]. When the increase due to the enhanced mixing caused by free convection effects is more than the decrease in pressure drop due to the decreased density and viscosity, the friction factors increase (as was found in this study). 


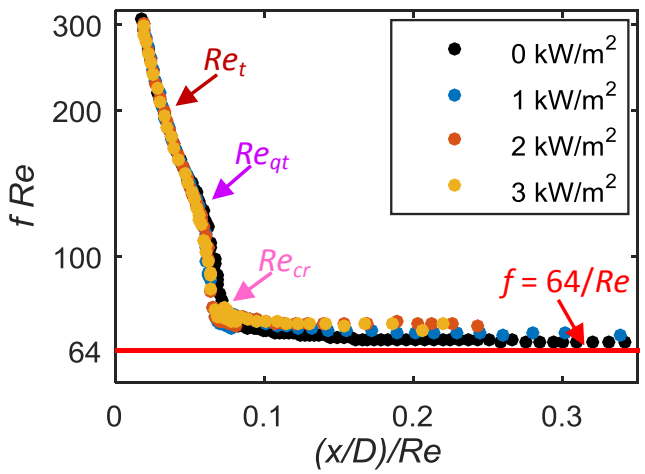

(a)

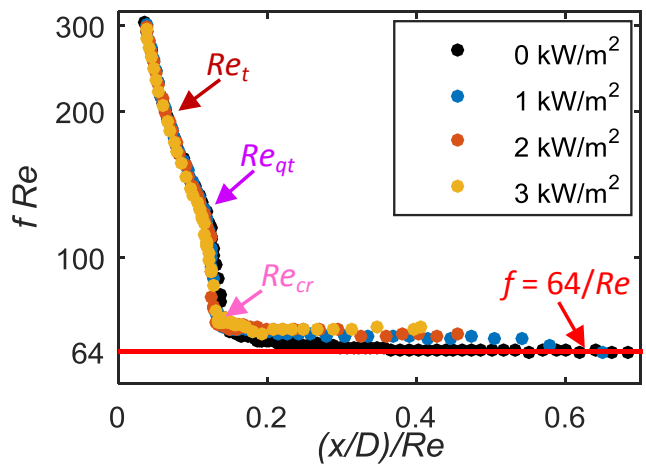

(c)

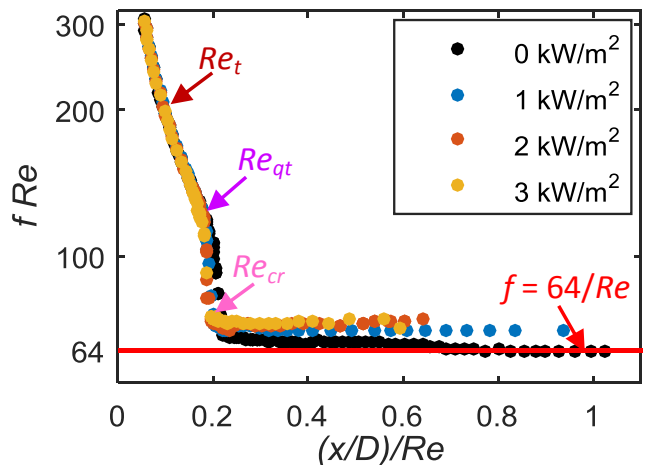

(e)

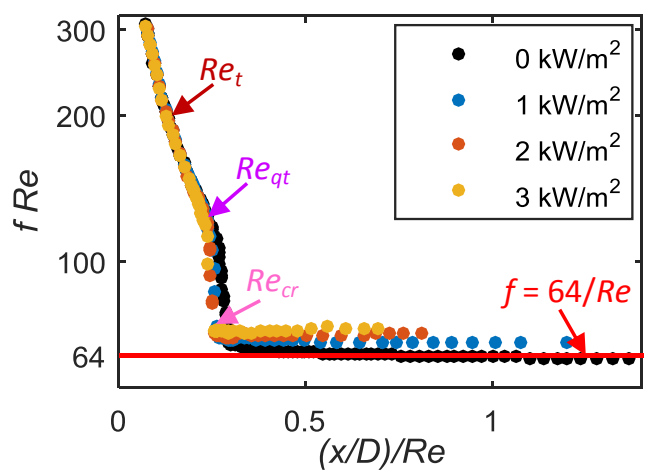

(g)

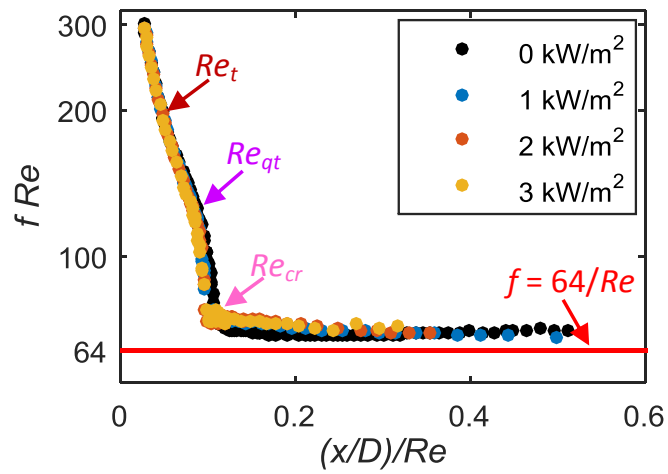

(b)

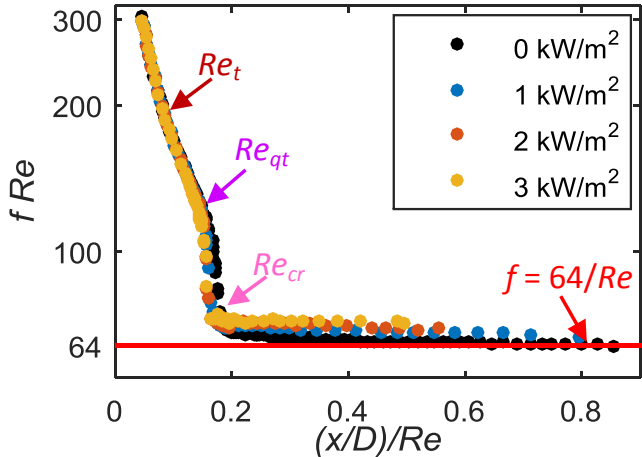

(d)

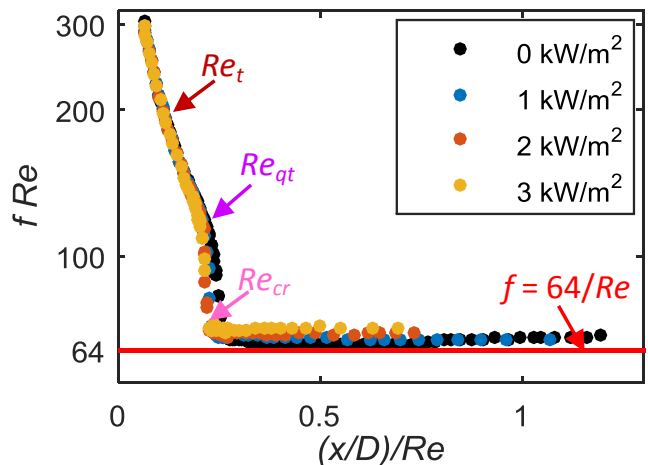

(f)

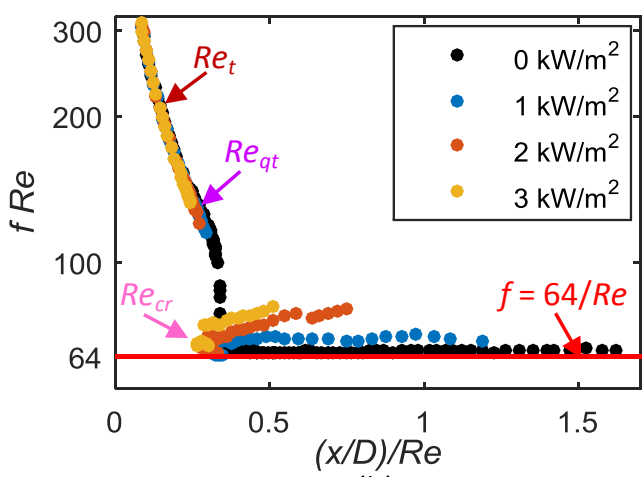

(h)

Fig. 6: Comparison of the product of the friction factor and Reynolds number ( $f R$ ) as a function of dimensionless axial distance $((x / D) / R e)$ for (a) $0 \mathrm{~m} \leq L \leq 2 \mathrm{~m}$, (b) $0 \mathrm{~m} \leq L \leq 3 \mathrm{~m}$, (c) $0 \mathrm{~m} \leq L \leq 4 \mathrm{~m}$, (d) $0 \mathrm{~m} \leq L \leq 5 \mathrm{~m}$, (e) $0 \mathrm{~m} \leq L \leq 6 \mathrm{~m}$, (f) $0 \mathrm{~m} \leq L \leq 7 \mathrm{~m}$, (g) $0 \mathrm{~m} \leq L \leq 8 \mathrm{~m}$, and (h) $8 \mathrm{~m} \leq L \leq 9.5 \mathrm{~m}$. The heat flux of $0 \mathrm{~kW} / \mathrm{m}^{2}$ indicate isothermal flow. 
Tam et al. [7] conducted experiments using different mixtures of ethylene glycol and water, therefore the Prandtl numbers varied between 4.3 and 46.3, while it ranged between 3 and 7 in this study. Everts and Meyer [34] investigated the fluid properties of water $(\operatorname{Pr} \approx 7)$ and ethylene glycol $(\operatorname{Pr} \approx 100)$ between temperatures of $20^{\circ} \mathrm{C}$ and $80^{\circ} \mathrm{C}$. It was found that the viscosity of ethylene glycol was not only an order of magnitude higher than that of water, but also a strong function of temperature. Furthermore, the specific heat and thermal conductivity of ethylene glycol were up to $50 \%$ and $60 \%$, respectively, less than water, which led to greater temperature differences. It was therefore concluded that, although free convection effects may be significant in the laminar flow regime when ethylene glycol was used, the increased viscosity in the centre of the tube restricted the free convection effects to the thermal boundary layer. This prevented free convection effects to lead to secondary flow, that assists in the diffusion of the heat from the surface to the centre of the tube, and increases the heat transfer coefficients and friction factors. Overall it can be concluded that when the flow was still developing, the laminar friction factors were increased due to entrance effects as well as free convection effects.

At the critical Reynolds number, $f R e$ increased significantly. Although the boundary between the quasi-turbulent and turbulent flow regimes was challenging to identify in Fig. 5, it became prominent in Fig. 6. In the quasi-turbulent flow regime, the gradient of $f R e$ increased (compared to the transitional flow regime), while it decreased (compared to the quasi-turbulent flow regime) in the turbulent flow regime.

\subsection{Heat transfer}

Fig. 7 compares the average Colburn $j$-factors of the different tube lengths as a function of Reynolds number at different heat fluxes. The solid red line indicates the Colburn $j$-factors calculated using the theoretical Nusselt number of 4.36, which is valid for fully developed forced convection laminar flow. From this figure it follows that the Colburn $j$-factors were significantly higher than for $N u=4.36$, due to free convection effects, as well as the fact that the flow was still developing. Metais and Eckert [49] considered free convection effects to be significant when the Nusselt numbers were more than $10 \%$ greater than the corresponding forced convection Nusselt numbers. At a Reynolds number of 1500 , the average fully developed Nusselt number (corresponding to the Colburn $j$-factors in Fig. 7(h)), was approximately 8.95 at a heat flux of $1 \mathrm{~kW} / \mathrm{m}^{2}$, and increased to 12.46 at a heat flux of $3 \mathrm{~kW} / \mathrm{m}^{2}$. As this is $105 \%$ and $186 \%$, respectively, greater than 4.36 , it can be concluded free convection effects were significant. 


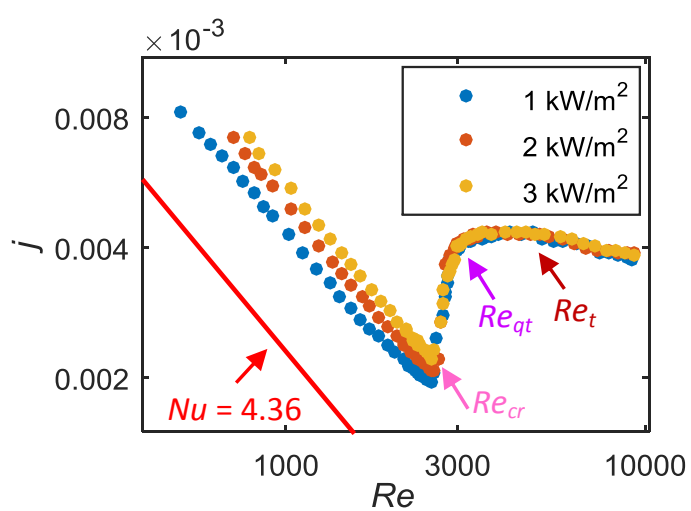

(a)

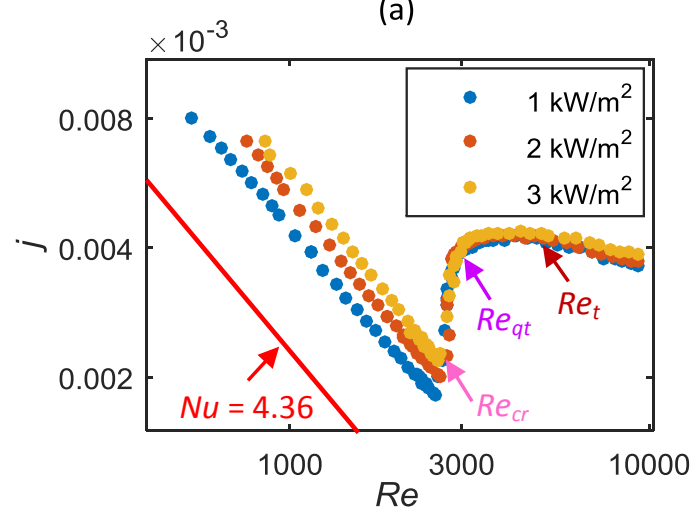

(c)

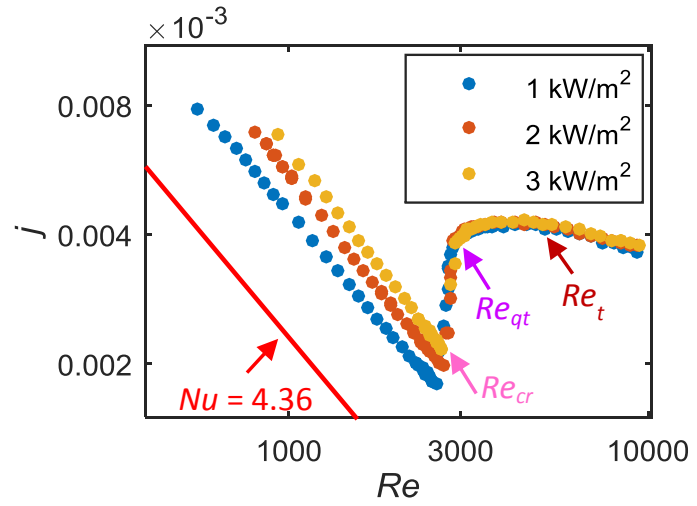

(e)

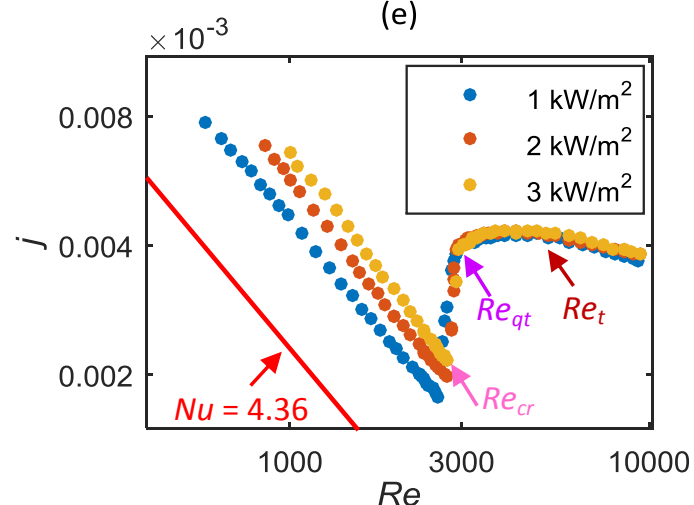

(g)

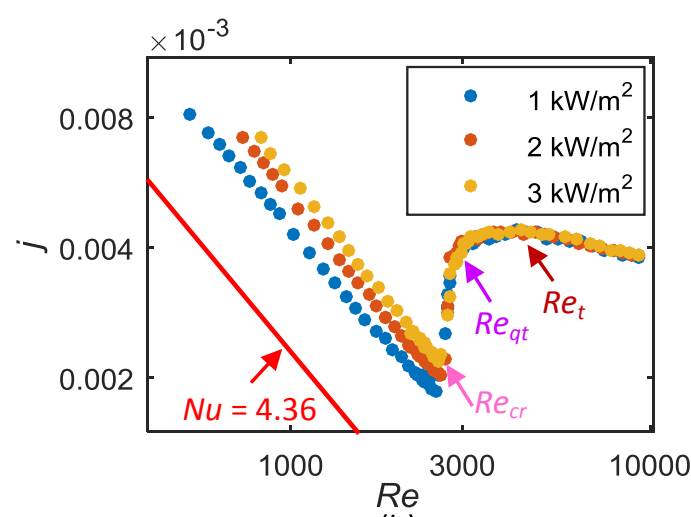

(b)

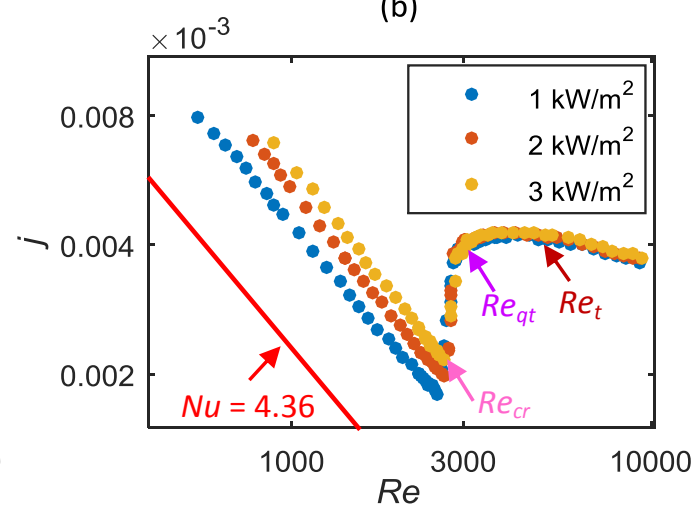

(d)

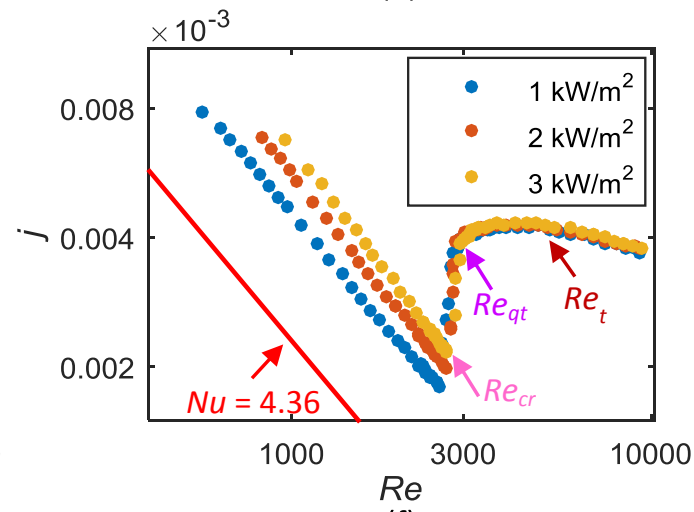

(f)

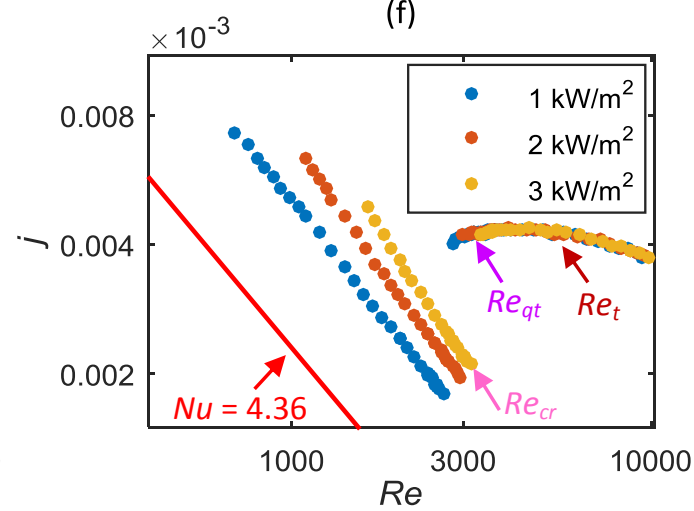

(h)

Fig. 7: Comparison of the average Colburn $j$-factor as a function of Reynolds number at different heat fluxes across (a) $0 \mathrm{~m} \leq L \leq 2 \mathrm{~m}$, (b) $0 \mathrm{~m} \leq L \leq 3 \mathrm{~m}$, (c) $0 \mathrm{~m} \leq L \leq 4 \mathrm{~m}$, (d) $0 \mathrm{~m} \leq L \leq 5 \mathrm{~m}$, (e) $0 \mathrm{~m} \leq L \leq 6 \mathrm{~m}$, (f) $0 \mathrm{~m} \leq L \leq 7 \mathrm{~m}$, (g) $0 \mathrm{~m} \leq L \leq 8 \mathrm{~m}$, and (h) $8 \mathrm{~m} \leq L \leq 9.5 \mathrm{~m}$. 
From Fig. 7(a) it follows that, at a Reynolds number of 1 500, the difference between the Colburn $j$-factors at heat fluxes of $1 \mathrm{~kW} / \mathrm{m}^{2}$ and $3 \mathrm{~kW} / \mathrm{m}^{2}$ was approximately $25 \%$, but increased to $61 \%$ when the flow was fully developed (Fig. 7(h)). Therefore, as the tube length increased and the flow approached fully developed flow, the difference between the Colburn $j$-factors of the different heat fluxes increased, since free convection effects increased with increasing thermal boundary layer thickness. This increase in laminar Colburn $j$-factors was also significantly more than for the laminar friction factors in Fig. 5.

Similar to the friction factor results in Fig. 5, the critical Reynolds number increased with increasing heat flux. Near the inlet of the test section $(0 \mathrm{~m}<L<2 \mathrm{~m}$ in Fig. 7(a)), transition started at Reynolds numbers of 2520 and 2532 at heat fluxes of $1 \mathrm{~kW} / \mathrm{m}^{2}$ and $3 \mathrm{~kW} / \mathrm{m}^{2}$, respectively. However, when the flow was fully developed $(8 \mathrm{~m}<L<9.5 \mathrm{~m}$ in Fig. $7(\mathrm{~h}))$, transition was delayed to Reynolds numbers of 2641 and 3142 for heat fluxes of $1 \mathrm{~kW} / \mathrm{m}^{2}$ and $3 \mathrm{~kW} / \mathrm{m}^{2}$, respectively. The difference between the critical Reynolds numbers of the two heat fluxes thus increased along the tube length, from a Reynolds number range of 12 (Fig. 7(a)) to 541 (Fig. 7(h)). Similar to the isothermal results in Fig. 4, Everts and Meyer [34] found that transition occurred at the same moment along the entire test section, and the increasing critical Reynolds numbers along the tube length was due to the decreasing viscosity with increasing temperature. The temperature gradient along the test section increased with increasing heat flux, which led to greater critical Reynolds number variations.

From Fig. 7 it also follows that the transition gradient, $T G_{j}$, increased not only as the flow approached fully developed flow, but also with increasing heat flux, since free convection effects caused the flow to transition faster from laminar to turbulent along the tube length [1]. Similar to Fig. 5(h), the severe fluctuations due to free convection effects caused the transitional flow regime to became negligible once the flow was fully developed (Fig. 7(h)), and the flow alternated between the laminar and quasi-turbulent flow regimes.

Everts and Meyer [34] found that although free convection effects did not significantly affect the magnitude of the heat transfer coefficients in the quasi-turbulent flow regime, it decreased the width of this regime, since the Reynolds number at which transition ended increased, while the Reynolds number at which the flow became fully turbulent remained unaffected. Similar results were obtained in Fig. 7(h), since free convection effects caused the width of the quasi-turbulent flow regime to decrease from a Reynolds number range of approximately 3200 to 2640 , when the heat flux was increased from $1 \mathrm{~kW} / \mathrm{m}^{2}$ to $3 \mathrm{~kW} / \mathrm{m}^{2}$. Furthermore, the width of the quasi-turbulent flow regime also decreased as the flow approached fully developed flow. From Fig. 7(a) and (h) it follows that at a heat flux of 
$3 \mathrm{~kW} / \mathrm{m}^{2}$, the width of the quasi-turbulent regime decreased from a Reynolds number range of 3010 when the flow was developing, to 2640 when the flow was fully developed. As expected, there was no significant difference between the results of the different tube lengths and heat fluxes in the turbulent flow regime, since the flow was fully developed and the free convection effects were suppressed by the velocity of the fluid.

\subsection{Relationship between pressure drop and heat transfer}

When comparing the friction factor results (Fig. 5) and Colburn j-factor results (Fig. 7) as a function of Reynolds number, it follows that the trends were similar. This is not unexpected since the Chilton-Colburn analogy [3], which was developed for laminar and turbulent flow over flat plates, determined that the relationship between friction factor (pressure drop) and Colburn $j$-factor (heat transfer) is directly proportional. It has however, not been shown before that this relationship is valid in the transitional flow regime.

As the pressure drop and heat transfer data was measured simultaneously during the experiments, the average friction factors and Colburn $j$-factors for $0 \mathrm{~m}<L<8 \mathrm{~m}$, at heat fluxes of $1 \mathrm{~kW} / \mathrm{m}^{2}$ and $3 \mathrm{~kW} / \mathrm{m}^{2}$, were plotted on the same graph in Fig. 8. Although the results are only given for this tube length and heat fluxes in this paper, graphs were generated for the other tube lengths and heat fluxes as well, and similar observations were made. The boundaries of the different flow regimes $\left(R e_{c r}, R e_{q t}\right.$ and $\left.R e_{t}\right)$ are indicated by the dotted lines, and are coloured according to the heat flux.

In the laminar flow regime, both friction factors and Colburn $j$-factors decreased with increasing Reynolds number, therefore both gradients were negative. At a fixed Reynolds number of 2370 , the increase in friction factors between the two heat fluxes was $4 \%$, while the increase in Colburn $j$-factors was $29 \%$. Therefore, free convection effects had a greater influence on the heat transfer coefficients than on the friction factors in the laminar flow regime.

At a heat flux of $3 \mathrm{~kW} / \mathrm{m}^{2}$, the gradients of both friction factors ( $\left.d f / d R e\right)$ and Colburn $j$ factors $(d j / d R e)$ changed from negative to positive at a Reynolds number of $2740\left(R e_{c r}\right)$, which indicated the start of the transitional flow regime [34]. In the transitional flow regime, both friction factors and Colburn $j$-factors increased with increasing Reynolds number, therefore the gradients were positive. Transition ended at a Reynolds number of approximately $3019\left(R e_{q t}\right)$, where the gradient of both the friction factor and the Colburn $j$ factor lines decreased compared to the transitional flow regime $\left((d f / d R e)_{Q T}<(d f / d R e)_{T G}\right.$ and $\left.(d j / d R e)_{Q T}<(d j / d R e)_{T G}\right)[34]$. 
In the quasi-turbulent flow regime, both the friction factors and Colburn $j$-factors first increased with increasing Reynolds number (although the gradients were significantly less than in the transitional flow regime), and then decreased as the Reynolds number was increased further, forming a concave curve. However, as the gradient of the Colburn $j$-factors were less than for the friction factors, the concave curve of the Colburn $j$-factors was flatter than for the friction factors. Near the end of the quasi-turbulent flow regime, the trends of the friction factors and Colburn $j$-factors were similar to the turbulent flow regime (decreased with increasing Reynolds number), however, it was not fully turbulent yet. From the Colburn $j$-factors results it follows that the flow only became fully turbulent at a Reynolds number of approximately $5955\left(R e_{t}\right)$, where both friction factors and Colburn $j$-factors decreased with increasing Reynolds number, and correlated very well with correlation of Allen and Eckert [5] and Ghajar and Tam [13]. This also corresponds to the findings of Everts and Meyer [34] of $R e_{t}=6000$.

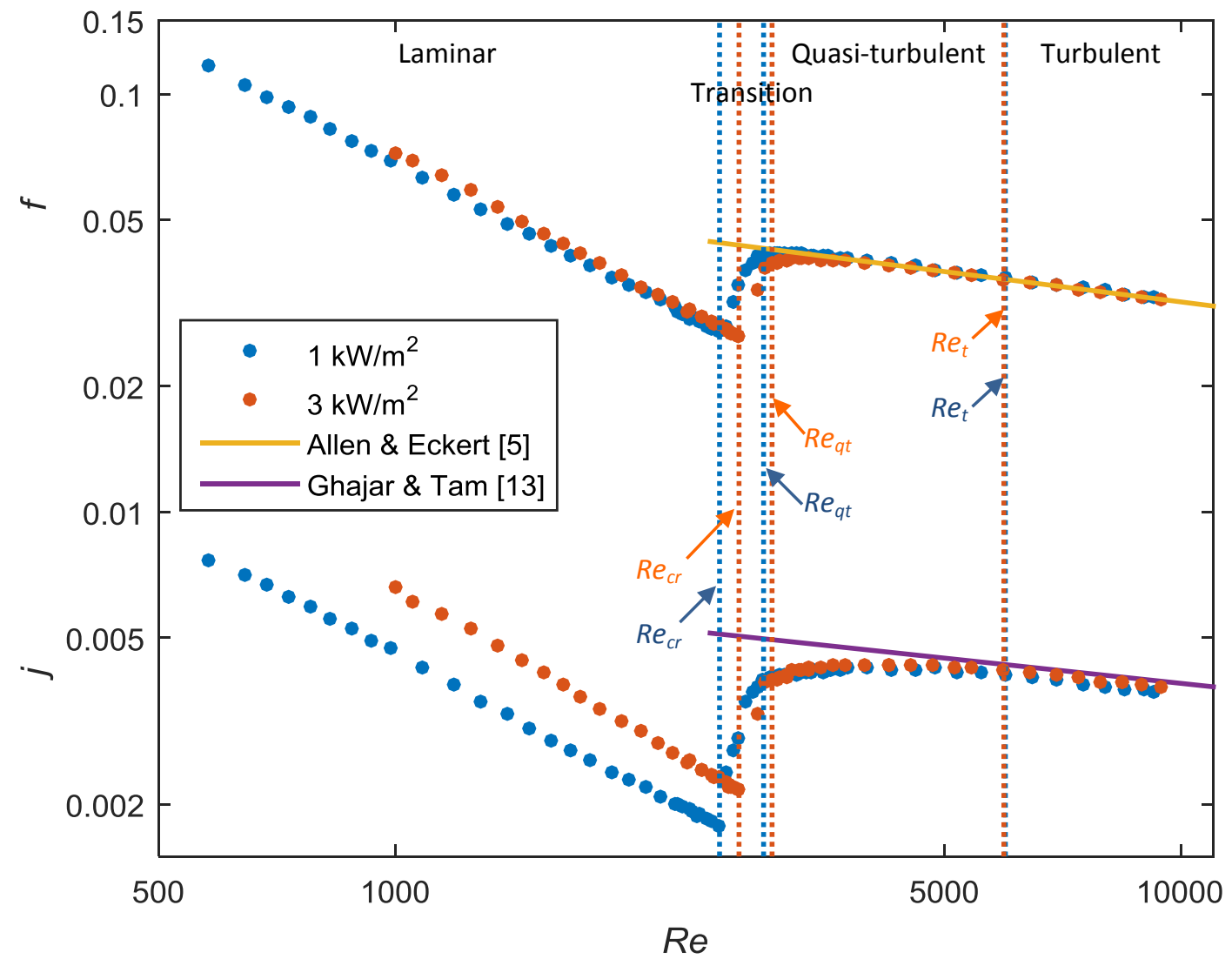

Fig. 8: Comparison of the heat transfer and pressure drop results in terms of the average Colburn $j$-factors and friction factors for $0 \mathrm{~m}<L<8 \mathrm{~m}$ as a function of Reynolds number, at heat fluxes of $1 \mathrm{~kW} / \mathrm{m}^{2}$ and $3 \mathrm{~kW} / \mathrm{m}^{2}$.

Overall, it can be concluded that the boundaries of the different flow regimes, especially the transitional flow regime, were the same for pressure drop and heat transfer, for all our 
experiments. This corresponds to the Chilton-Colburn analogy [3], which was developed for laminar and turbulent flow over flat plates, that shows that there is a direct relationship between friction factor (pressure drop) and Colburn $j$-factor (heat transfer). Similar findings were also made by Everts [50] and Meyer and Abolarin [26]. However, Tam et al. [7] found that the transition region, $\Delta R e$, was wider for heat transfer than for pressure drop. A possible explanation for this is that the authors considered the quasi-turbulent flow regime as part of the transitional flow regime when the Colburn $j$-factors were investigated, while it was considered as part of the turbulent flow regime when the friction factors were investigated.

To investigate the relationship between pressure drop and heat transfer, $f / j$-factors were obtained by dividing the friction factors by the Colburn $j$-factors. The results are summarised in Fig. 9 for tube lengths of $0 \mathrm{~m}<L<2 \mathrm{~m}$ (Fig. 5(a) and Fig. 7(a)) and $0 \mathrm{~m}<L<8 \mathrm{~m}$ (Fig. $5(\mathrm{~g})$ and Fig. $7(\mathrm{~g}))$, at a heat flux of $3 \mathrm{~kW} / \mathrm{m}^{2}$. From this figure it follows that the $\mathrm{f} / \mathrm{j}$-factors in the laminar flow regime increased with increasing Reynolds number. As the results differed significantly for the two tube lengths, it can be concluded that the $f / j$-factors in the laminar flow regime is affected by developing flow and free convection effects. In the transitional flow regime, the $f / j$-factors decreased significantly with increasing Reynolds number, however, this decrease was slightly less for $0 \mathrm{~m}<L<2 \mathrm{~m}$ than for $0 \mathrm{~m}<L<8 \mathrm{~m}$. Although the $f / j$-factors continued to decrease in the quasi-turbulent flow regime, the gradient of the $f / j$-factors increased compared to the transitional flow regime, and approached zero in the turbulent flow regime. Furthermore, as the Reynolds number was increased, the difference in the $f / j$-factors of the two tube lengths decreased, and became negligible in the turbulent flow regime since the flow was fully developed and free convection effects were suppressed.

From Fig. 9 it follows that the $f / j$-factors can also be used to identify the boundaries of the different flow regimes, when pressure drop and heat transfer are investigated simultaneously. This can be used in addition to the criteria for the flow regime boundaries which were developed by Everts and Meyer [34], and will also ensure a better understanding of the tradeoff between pressure drop and heat transfer in the different flow regimes. 


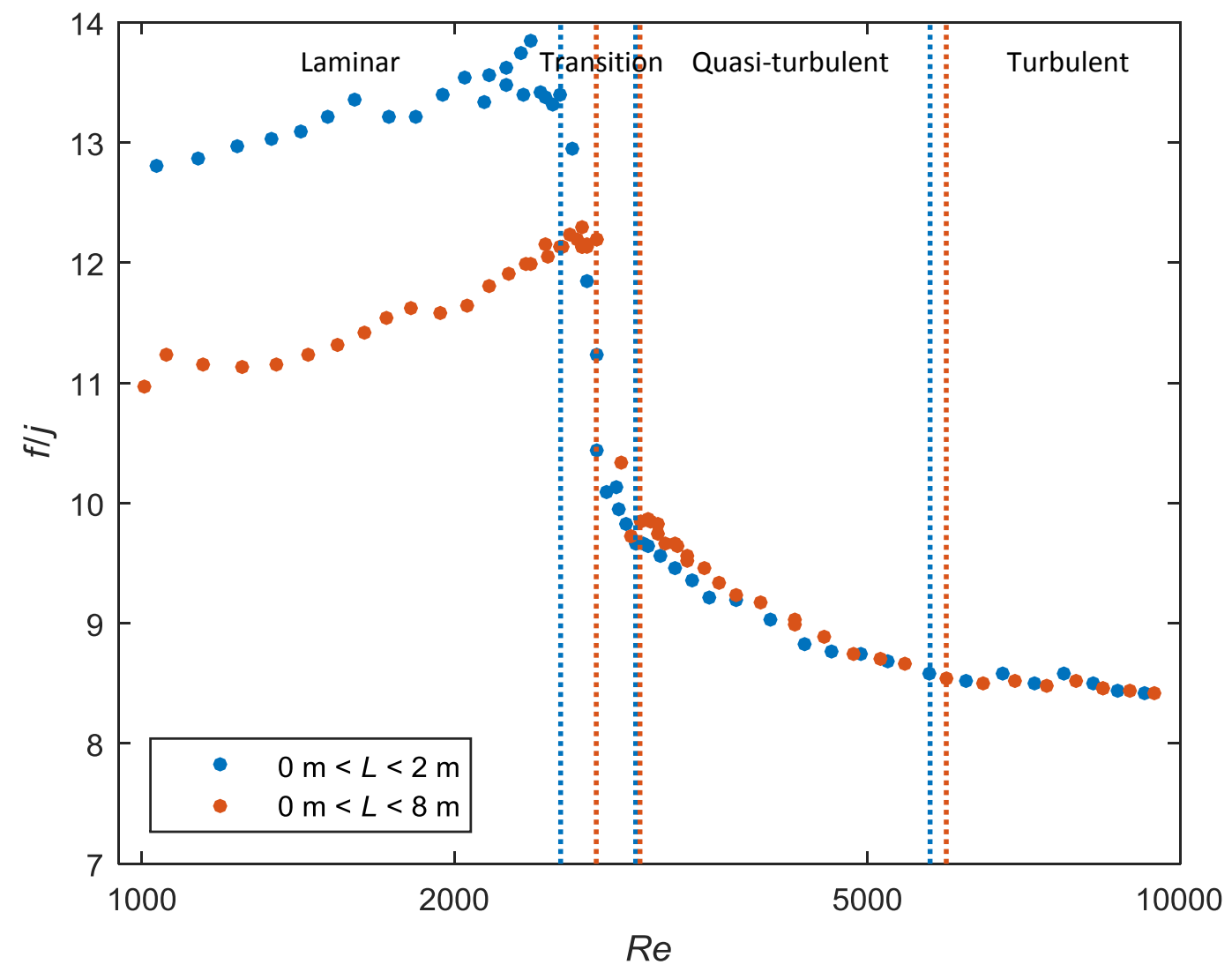

Fig. 9: Comparison of the average friction factors divided by the Colburn $j$-factors as a function of Reynolds number for $0 \mathrm{~m}<L<2 \mathrm{~m}$ and $0 \mathrm{~m}<L<8 \mathrm{~m}$ at a heat flux of $3 \mathrm{~kW} / \mathrm{m}^{2}$.

Fig. 10 compares the $f / j$-factors of the different tube lengths at different heat fluxes. From this figure it follows that the laminar $f / j$-factors decreased significantly with increasing heat flux, thus free convection effects. Furthermore, at a heat flux of $1 \mathrm{~kW} / \mathrm{m}^{2}$, the laminar $f / j$ factors were approximately 16 for $0 \mathrm{~m}<L<2 \mathrm{~m}$ (Fig. 10(a)), but decreased to approximately 14 when the flow was fully developed (Fig. 10(h)). As the Reynolds number was increased, free convection effects decreased and the difference between the $f / j$-factors of the different tube lengths and heat fluxes decreased and became negligible. It can be concluded from this graph that the $f / j$-factors in the laminar flow regime is a function of Grashof number (free convection effects), while it is a function of Reynolds number in the other flow regimes. 


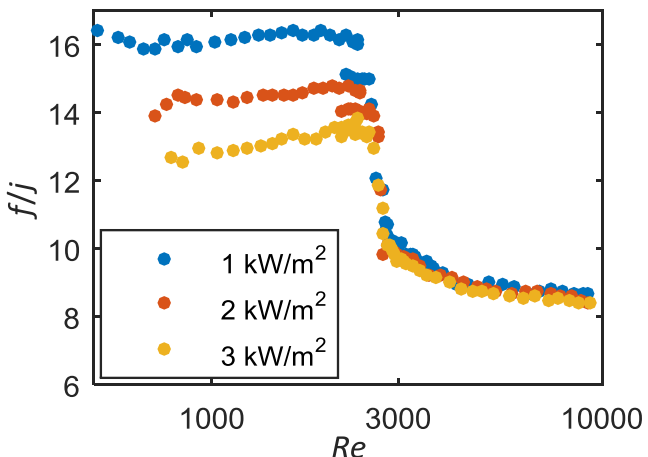

(a)

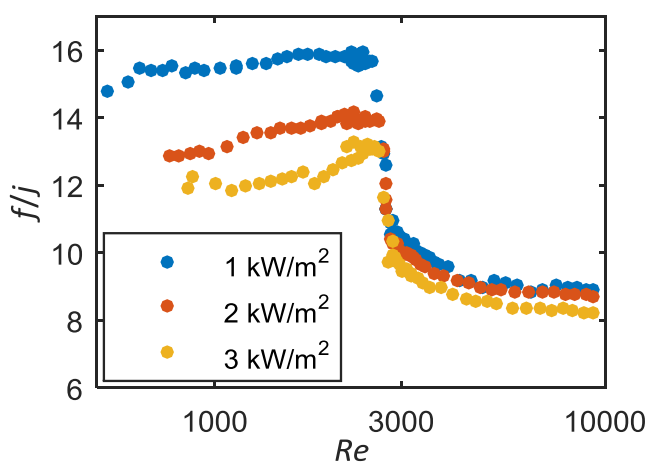

(c)

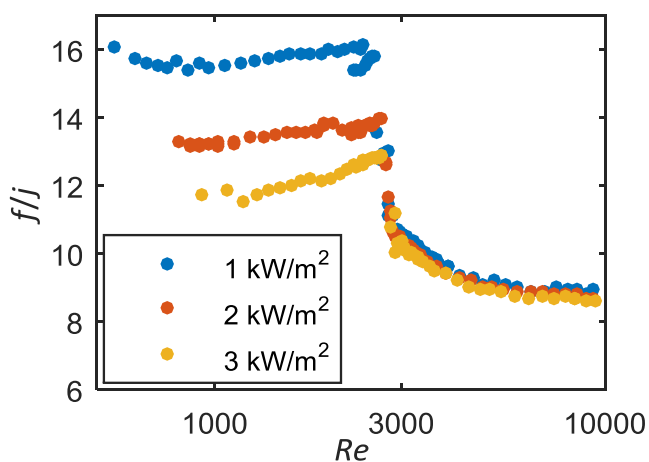

(e)

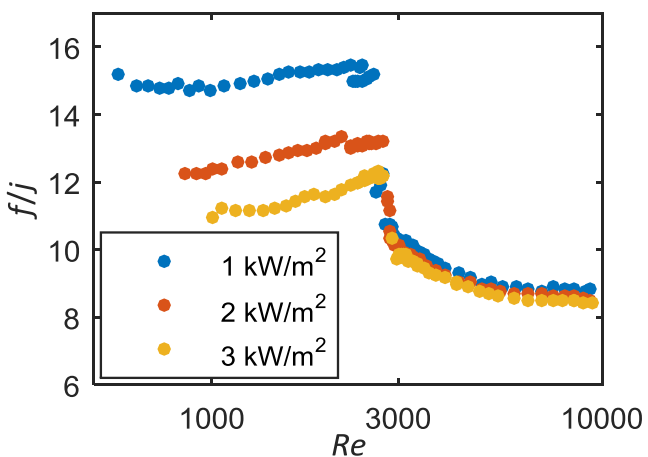

(g)

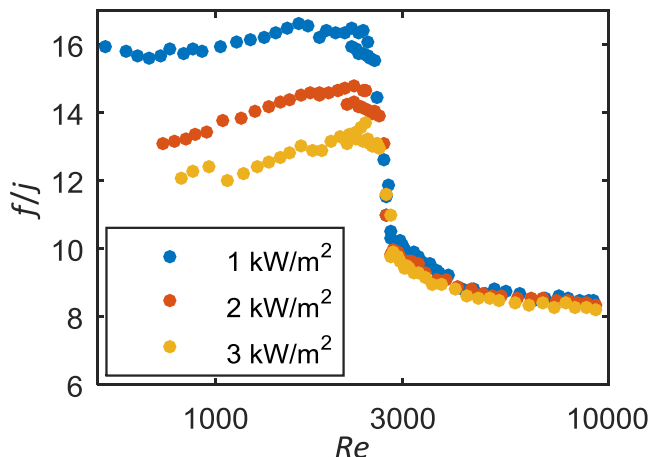

(b)

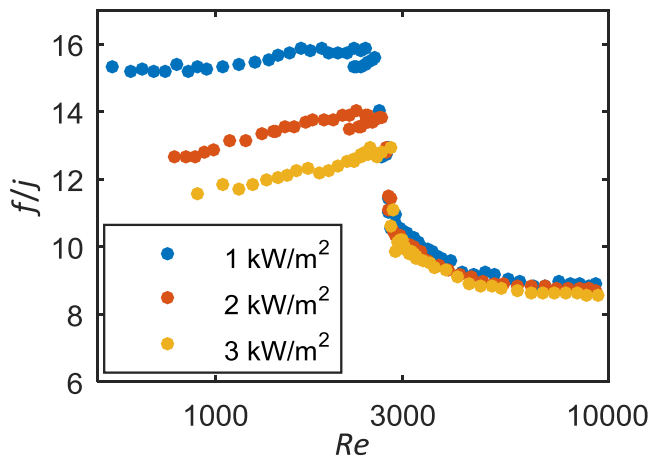

(d)

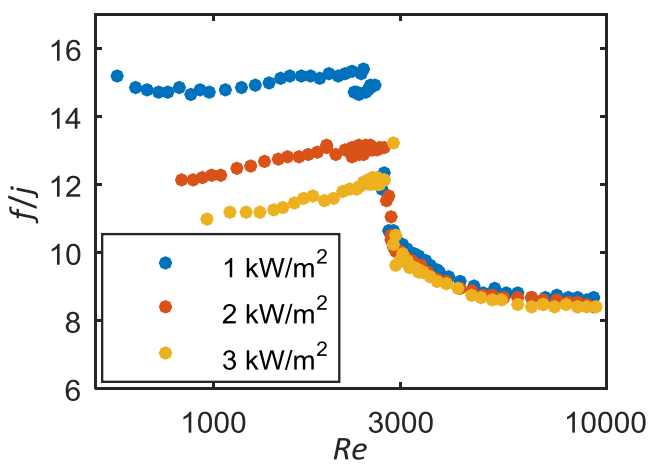

(f)

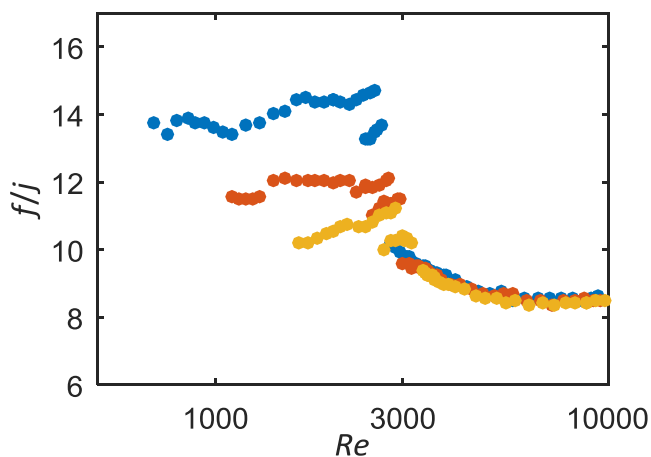

(h)

Fig. 10: Comparison of the average friction factors divided by the Colburn $j$-factors as a function of Reynolds number at different heat fluxes across (a) $0 \mathrm{~m} \leq L \leq 2 \mathrm{~m}$, (b) $0 \mathrm{~m} \leq L \leq 3 \mathrm{~m}$, (c) $0 \mathrm{~m} \leq L \leq 4 \mathrm{~m}$, (d) $0 \mathrm{~m} \leq L \leq 5 \mathrm{~m}$, (e) $0 \mathrm{~m} \leq L \leq 6 \mathrm{~m}$, (f) $0 \mathrm{~m} \leq L \leq 7 \mathrm{~m}$, (g) $0 \mathrm{~m} \leq L \leq 8 \mathrm{~m}$, and (h) $8 \mathrm{~m} \leq L \leq 9.5 \mathrm{~m}$. 


\subsection{Correlations}

Correlations were developed to determine the relationship between heat transfer and pressure drop ( $f / j$-factors) of developing and fully developed flow in the different flow regimes. These correlations were then combined with Eq. (11), to obtain a correlation for the average friction factor as a function of average Nusselt number. As these friction factor correlations are a function of Nusselt number, average Nusselt numbers correlations for developing and fully developed flow in the different flow regimes, were also developed. The ranges and performance of the friction factor correlations (Section 7.4.1) and Nusselt number correlations (Section 7.4.2) are summarised in Section 7.4.3. It should be noted that although the average friction factor and Nusselt number correlations are not explicitly a function of tube length, $L$, it is valid for developing and fully developed data, since the bulk Reynolds number, Grashof number and Prandtl number for tube length $L(x)$, are used.

The friction factors and Colburn $j$-factors were calculated across eight different tube lengths, at three different heat fluxes. The solid markers in Fig. 11 to Fig. 14 represent the results at a heat flux of $1 \mathrm{~kW} / \mathrm{m}^{2}$, while the circles and diamonds represent the results at $2 \mathrm{~kW} / \mathrm{m}^{2}$ and $3 \mathrm{~kW} / \mathrm{m}^{2}$, respectively. Seven of the eight tube lengths contained both developing and fully developed flow (depending on the Reynolds number and heat flux), while the black markers $(8 \mathrm{~m}<L<9.5 \mathrm{~m})$ contained fully developed flow only.

\subsubsection{Average friction factors}

To determine the relationship between pressure drop and heat transfer for mixed convection conditions in the laminar flow regime, the $f / j$-factors were plotted against Grashof numbers in Fig. 11(a), and against the modified Grashof numbers in Fig. 11(c). A power curve fit was done through all the data (developing and fully developed flow) in Fig. 11(a) to obtain the following correlation:

$$
\frac{f}{j}=109.71 G r^{-0.215}
$$

Therefore, the following correlation was obtained to calculate the average friction factor as a function of average Nusselt number and bulk Grashof number:

$$
f=\frac{109.71 N u}{\operatorname{Re}_{\operatorname{Pr}}^{1 / 3} G r^{0.215}}
$$




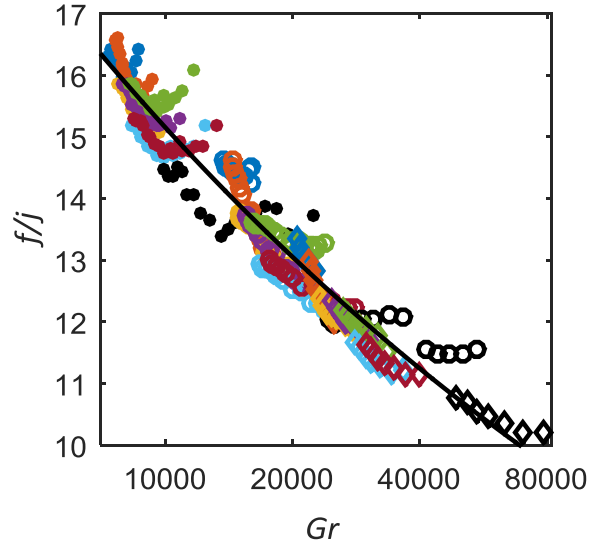

(a)

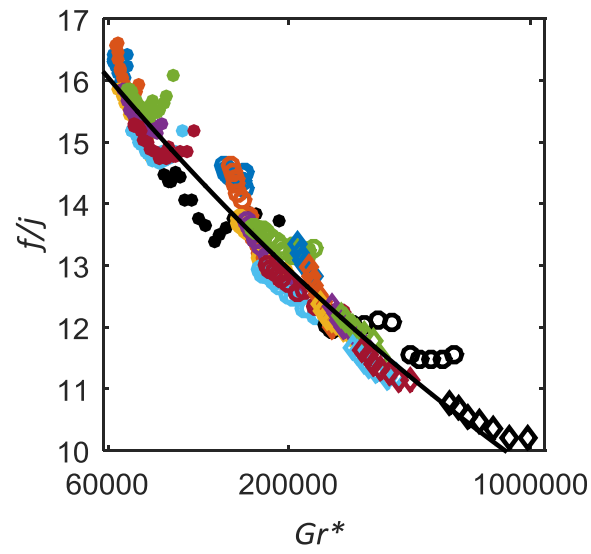

(c)

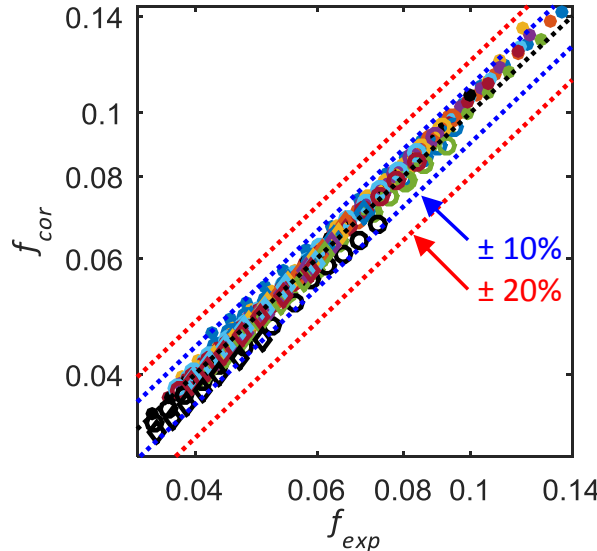

(b)

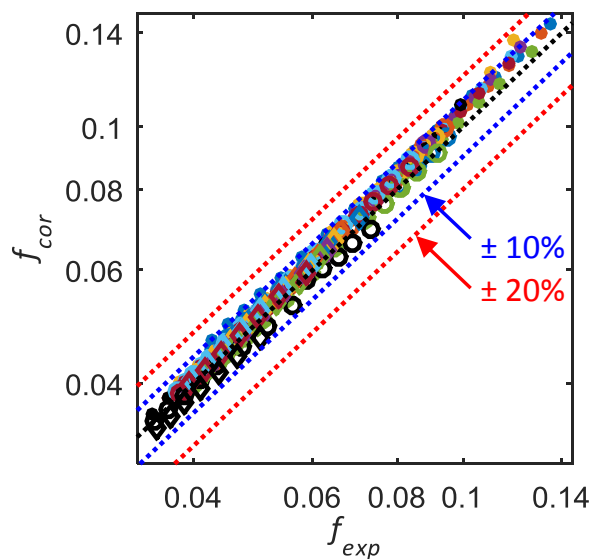

(d)

Fig. 11: Comparison of (a) ( $f / j)$ as a function of Reynolds number, (b) deviation between Eq. (17) and experimental data, (c) $(f / j)$ as a function of Reynolds number and (d) deviation between Eq. (19) and experimental data. The solid markers represent the results at a heat flux of $1 \mathrm{~kW} / \mathrm{m}^{2}$, while the circles and diamonds represent the results at $2 \mathrm{~kW} / \mathrm{m}^{2}$ and $3 \mathrm{~kW} / \mathrm{m}^{2}$, respectively. The data is coloured according to the tube lengths, as specified in the legend.

The same procedure was then repeated for the bulk modified Grashof number in Fig. 11(c), since the temperature differences (required to calculate the Grashof number) are not always known, while the heat fluxes usually are:

$$
\frac{f}{j}=115.01 G r^{*-0.179}
$$

The average laminar friction factor as a function of average Nusselt number and bulk modified Grashof number can therefore be calculated using the following correlation:

$$
f=\frac{115.01 N u}{\operatorname{Re} r^{1 / 3} G r^{* 0.179}}
$$


As the $f / j$-factors in the transitional, quasi-turbulent and turbulent flow regimes were a stronger function of Reynolds number than Grashof number, a single correlation for these three flow regimes was obtained by dividing the $f / j$-factors by $\operatorname{Pr}^{0.42}$. The results $\left((f / j) / \operatorname{Pr}^{0.42}\right)$ were plotted against Reynolds number in Fig. 12(a), and a rational curve-fit was done to obtain the following correlation:

$$
\frac{(f / j)}{P r^{0.42}}=\frac{3.74 R e-8066}{R e-2320}
$$

The following correlation was obtained to calculate the average friction factor as a function of average Nusselt number for developing and fully developed flow in the transitional, quasi-turbulent and turbulent flow regimes:

$$
f=\left(\frac{3.74 R e-8066}{R e-2320}\right) \frac{N u}{\operatorname{RePr} 0.087}
$$

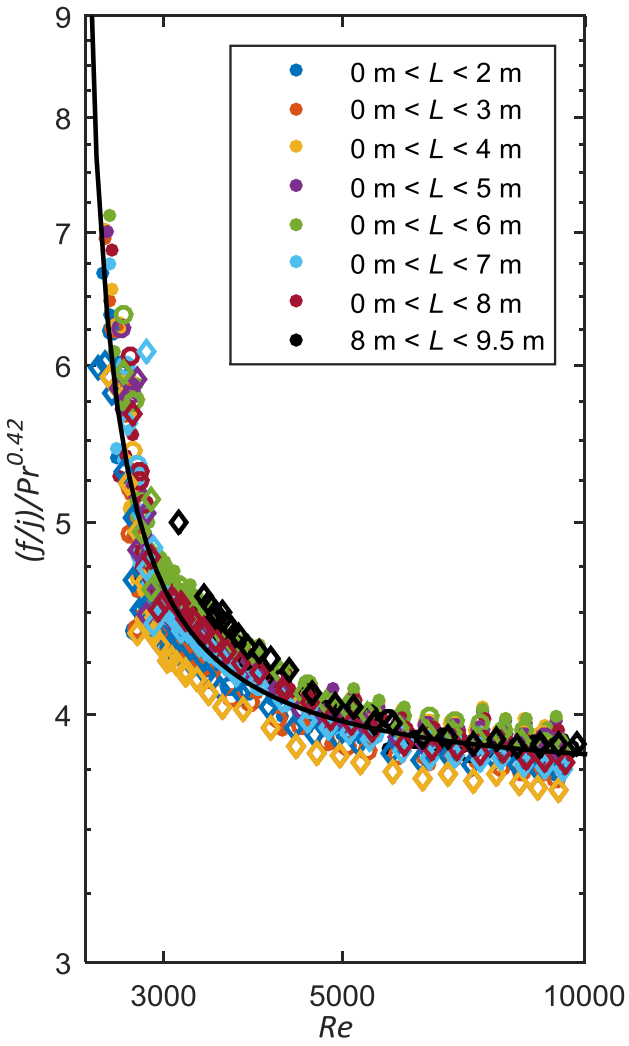

(a)

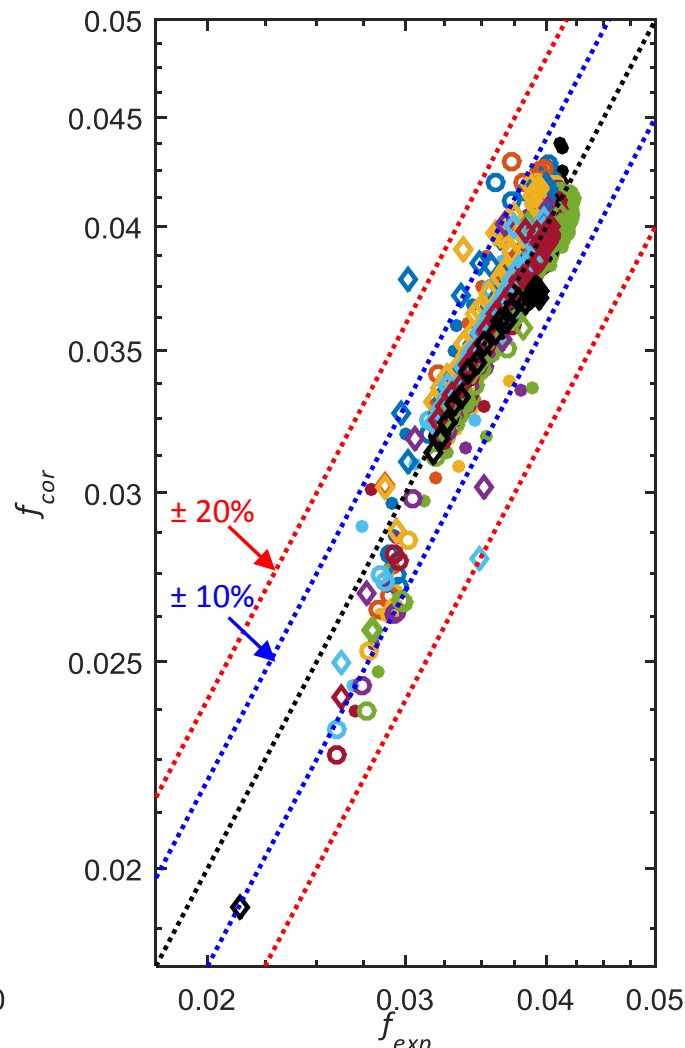

(b)

Fig. 12: (a) Comparison of $(\mathrm{f} / \mathrm{j}) / \mathrm{Pr}^{0.42}$ as a function of Reynolds number and (b) deviation between Eq. (21) and experimental data. The solid markers represent the results at a heat flux of $1 \mathrm{~kW} / \mathrm{m}^{2}$, while the circles and diamonds represent the results at $2 \mathrm{~kW} / \mathrm{m}^{2}$ and $3 \mathrm{~kW} / \mathrm{m}^{2}$, respectively. The data is coloured according to the tube lengths, as specified in the legend. 


\subsubsection{Average Nusselt numbers}

As Eqs. (17) and (19) are functions of the average Nusselt numbers, the following correlations, which were developed by Meyer and Everts [1], can be used to calculate the average Nusselt numbers across tube lengths $L(x)$, as a function of bulk Grashof numbers and bulk modified Grashof numbers, respectively:

$$
\begin{gathered}
N u=4.36+N u_{1}+N u_{2} \\
N u_{1}=\frac{1}{L(x)}\left(-0.84 \operatorname{Pr}^{-0.2} L t_{M C D}+0.72(\operatorname{ReD})^{0.54} \operatorname{Pr}^{0.34} L t_{M C D}^{0.46}\right) \\
N u_{2}=\frac{1}{L(x)}\left(0.207 G r^{0.305}-1.19\right) \operatorname{Pr}^{0.42}(\operatorname{ReD})^{-0.08}\left(L(x)-L t_{M C D}\right) \\
L t_{M C D}=\frac{2.4 \operatorname{RePr}^{0.6} D}{G r^{0.57}} \text { for } L(x)>L t_{M C D} \\
L t_{M C D}=L(x) \text { for } L(x)<L t_{M C D} \\
N u_{1}=\frac{1}{L(x)}\left(-0.84 P r^{-0.2} L t_{M C D}+0.72(\operatorname{ReD})^{0.54} \operatorname{Pr}^{0.34} L t_{M C D}^{0.46}\right) \\
\frac{1}{L(x)}\left(0.202 G r^{* 0.254}-1.23\right) P r^{0.39}\left(\operatorname{ReD}^{-0.06}\left(L(x)-L t_{M C D}\right)\right. \\
L t_{M C D}=\frac{2.1 \operatorname{RePr}^{0.6} D}{G r^{* 0.45}} \text { for } L(x)>L t_{M C D} \\
L t_{M C D}=L(x) \text { for } L(x)<L t_{M C D}
\end{gathered}
$$

It should be noted that the average Nusselt number in Eqs. (17) and (19) is a function of $L$, as indicated in Eqs. (22) and (23). Therefore, the correlations can be used for both developing and fully developed flow.

To develop a correlation to predict the average Nusselt numbers of developing flow in the transitional flow regime, the Nusselt numbers were divided by $\operatorname{Gr}^{-0.04}$ and $\operatorname{Pr}^{2}$. The results $N u G r^{0.04} / \mathrm{Pr}^{2}$ are plotted as a function of Reynolds number in Fig. 13(a) and the following transitional flow correlation was obtained with a linear curve-fit:

$$
N u=(0.00108 R e-2.49) G r^{-0.04} \mathrm{Pr}^{2}
$$

Gnielinski [51] proposed to use linear interpolation between the Nusselt numbers for laminar flow at a Reynolds number of 2300 , and the Nusselt numbers for turbulent flow at a Reynolds number of 10000 , to calculate the Nusselt numbers in the transitional flow regime. 
However, to improve the accuracy of the heat transfer coefficients in the transitional flow regime, Gnielinski [33] proposed to change the turbulent Reynolds number to 4000 [28]. Everts and Meyer [34] found that both the start and end of transition was affected by free convection and varied along the tube length, while the method of Gnielinski did not account for free convection effects or developing flow. Therefore, although Eq. (24) also predicts the Nusselt numbers to increase linearly in the transitional flow regime, it accounts for free convection effects and does not require interpolation.

The same procedure was used for the bulk modified Grashof number, and the following correlation for transitional flow was obtained by doing a linear curve-fit through the results in Fig. 13(c):

$$
N u=(0.00087 R e-2.01) G r^{*-0.01} \mathrm{Pr}^{2}
$$

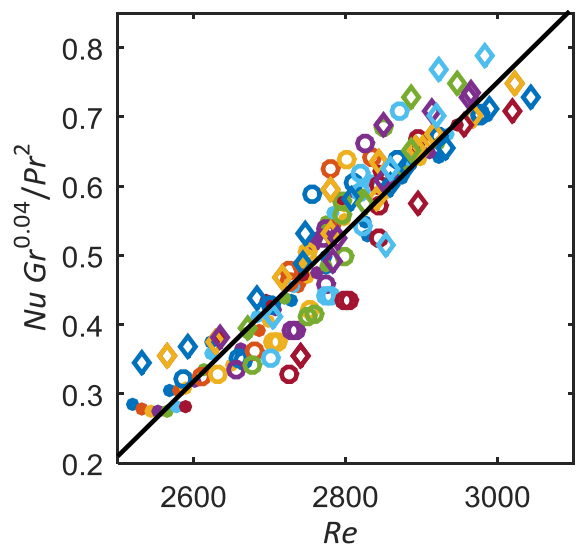

(a)

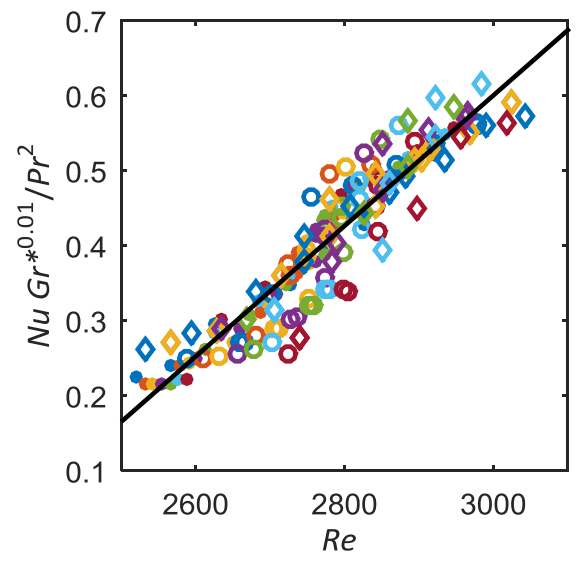

(c)

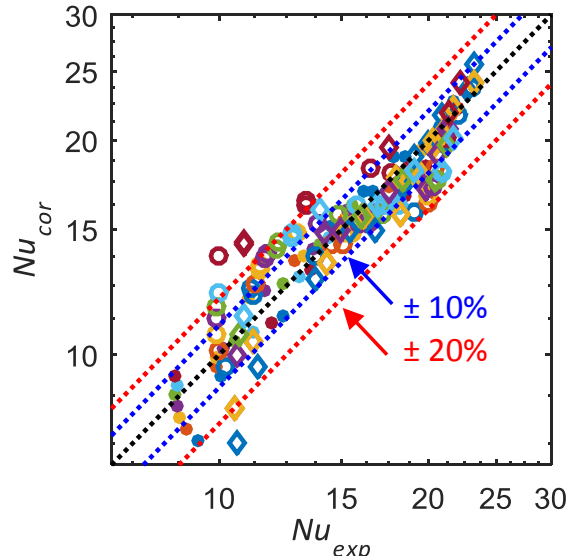

(b)

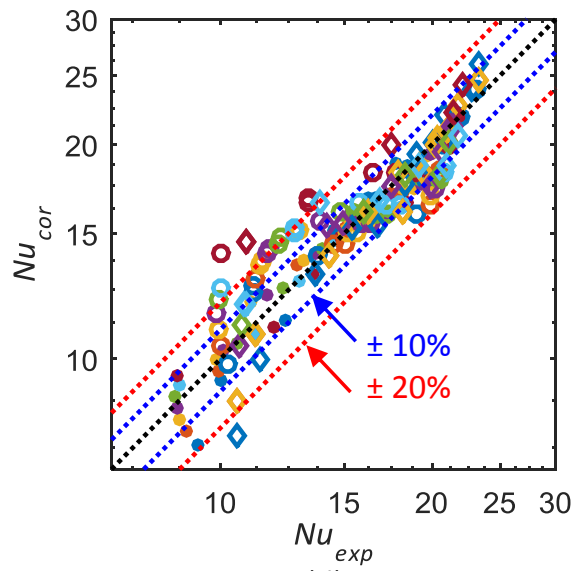

(d)

Fig. 13: Comparison of (a) $\mathrm{Nu} \mathrm{Gr}^{0.04} / \mathrm{Pr}^{2}$ as a function of Reynolds number, (b) deviation between Eq. (24) and experimental data, (c) $\mathrm{NuGr} \mathrm{Gr}^{0.01} / \mathrm{Pr}^{2}$ as a function of Reynolds number and (d) deviation between Eq. (25) and experimental data. The solid markers represent the results at a heat flux of $1 \mathrm{~kW} / \mathrm{m}^{2}$, while the circles and diamonds represent the results at $2 \mathrm{~kW} / \mathrm{m}^{2}$ and $3 \mathrm{~kW} / \mathrm{m}^{2}$, respectively. The data is coloured according to the tube lengths, as specified in the legend. 
From Fig. 7 it follows that the heat transfer coefficients in the quasi-turbulent and turbulent flow regimes were a strong function of Reynolds number and were not significantly affected by free convection effects. It was found by iteration that a correlation to predict the average Nusselt numbers in the quasi-turbulent and turbulent flow regimes, can be obtained when the Nusselt numbers were divided by $\operatorname{Pr}^{0.42}$. The results $\mathrm{Nu} \mathrm{Pr}^{0.42}$ are plotted as a function of (Re-1000) in Fig. 14(a), and a power curve-fit was done to obtain the following correlation:

$$
N u=\left(0.417(R e-1000)^{0.499}-8.2\right) \operatorname{Pr}^{0.42}
$$

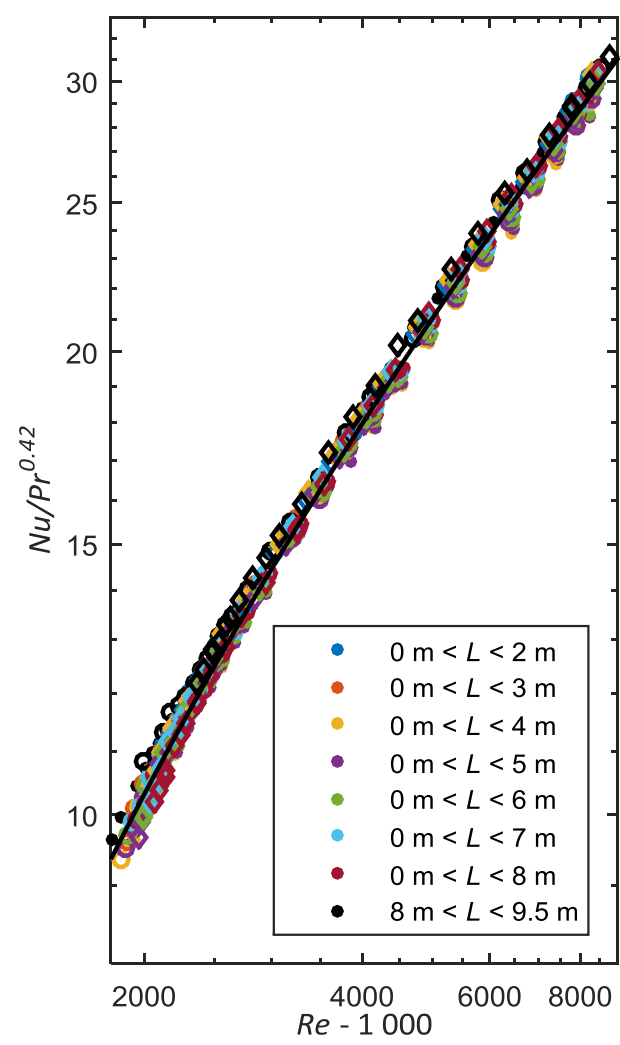

(a)

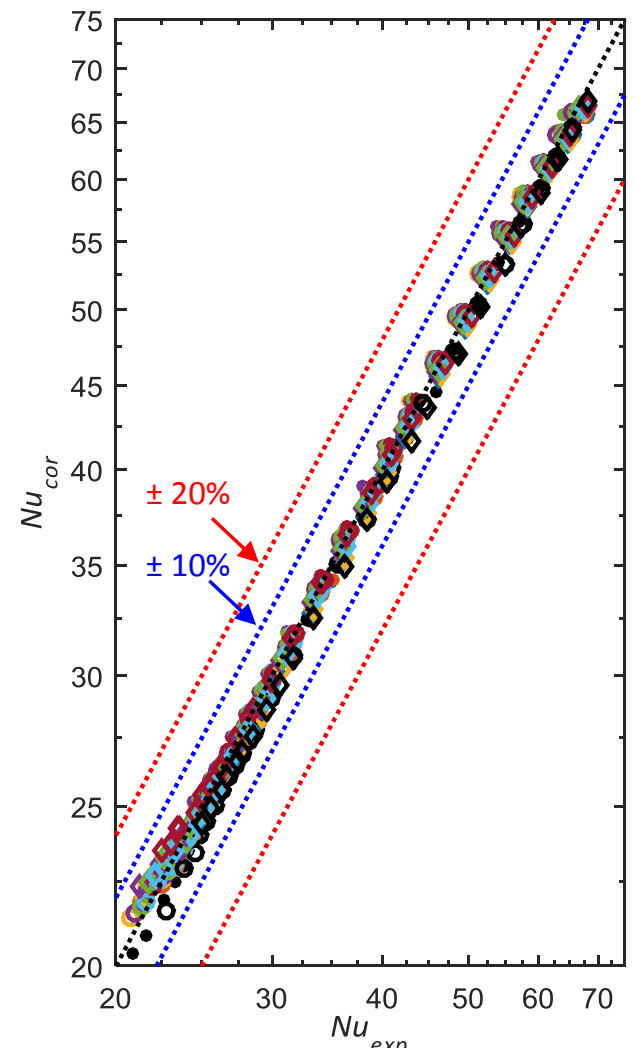

(b)

Fig. 14: Comparison of (a) $\mathrm{Nu} / \mathrm{Pr}^{0.42}$ as a function of $(\mathrm{Re}-1000)$ and (b) deviation between Eq. (26) and experimental data. The solid markers represent the results at a heat flux of $1 \mathrm{~kW} / \mathrm{m}^{2}$, while the circles and diamonds represent the results at $2 \mathrm{~kW} / \mathrm{m}^{2}$ and $3 \mathrm{~kW} / \mathrm{m}^{2}$, respectively. The data is coloured according to the tube lengths, as specified in the legend.

The method of Churchill and Usagi [52] was used to obtain a single correlation that is valid for all four flow regimes:

$$
N u=\left[N u_{1}^{10}+\left(N u_{2}^{-10}+N u_{3}^{-10}\right)^{-1}\right]^{0.1}
$$


Eq. (22) (laminar flow), Eq. (24) (transitional flow) and Eq. (26) (quasi-turbulent and turbulent flow) should be used to calculate $N u_{1}, N u_{2}$, and $N u_{3}$, respectively, in terms of the Grashof number. Similarly, Eq. (23) (laminar flow), Eq. (25) (transitional flow) and Eq. (26) (quasi-turbulent and turbulent flow) should be used to calculate $N u_{1}, N u_{2}$, and $N u_{3}$, respectively, in terms of the modified Grashof number.

\subsubsection{Summary and performance of correlations}

Table 2 summarises the valid ranges and performances of the average friction factor and average Nusselt number correlations for developing and fully developed flow, which were developed in this study.

Table 2: Summary of the ranges and performance of the average friction factor (Section 7.4.1) and average Nusselt number (Section 7.4.2) correlations.

\begin{tabular}{|c|c|c|c|c|c|c|c|}
\hline & Eq. & $\begin{array}{l}\text { Data } \\
\text { points }\end{array}$ & $\begin{array}{l} \pm 5 \% \\
{[\%]}\end{array}$ & $\begin{array}{c} \pm 10 \% \\
{[\%]}\end{array}$ & $\begin{array}{c} \pm 20 \% \\
{[\%]}\end{array}$ & $\begin{array}{l}\text { Ave } \\
{[\%]}\end{array}$ & Range \\
\hline \multicolumn{8}{|c|}{ Friction factors } \\
\hline \multirow{2}{*}{ Laminar } & (17) & 495 & 92 & 100 & 100 & 2.4 & \multirow{2}{*}{$\begin{array}{c}48 \leq \operatorname{Re} \leq 3217 \\
2.9 \leq \operatorname{Pr} \leq 282 \\
5.5 \leq G r \leq 4.5 \times 10^{4} \\
41 \leq G r^{*} \leq 7.3 \times 10^{6}\end{array}$} \\
\hline & (19) & 495 & 95 & 100 & 100 & 2.2 & \\
\hline $\begin{array}{l}\text { Transitional, } \\
\text { quasi-turbulent } \\
\text { and turbulent }\end{array}$ & $(21)$ & 834 & 85 & 97 & 99.9 & 2.8 & $\begin{aligned} 2483 & \leq R e \leq 9787, \\
5.4 & \leq \operatorname{Pr} \leq 6.9, \\
8.9 \times 10^{2} & \leq G r \leq 3.2 \times 10^{4}, \\
5.9 \times 10^{4} & \leq G r^{*} \leq 3.7 \times 10^{5}\end{aligned}$ \\
\hline \multicolumn{8}{|c|}{ Nusselt numbers } \\
\hline \multirow{2}{*}{ Laminar } & (22) & 495 & 74 & 98 & 100 & 3.6 & \multirow{2}{*}{$\begin{array}{c}48 \leq R e \leq 3217 \\
2.9 \leq \operatorname{Pr} \leq 282 \\
5.5 \leq G r \leq 4.5 \times 10^{4} \\
41 \leq G r^{*} \leq 7.3 \times 10^{6}\end{array}$} \\
\hline & (23) & 495 & 75 & 95 & 100 & 3.6 & \\
\hline \multirow{2}{*}{ Transitional } & (24) & 179 & 51 & 76 & 95 & 7.1 & \multirow{2}{*}{$\begin{aligned} 2520 & \leq R e \leq 3361, \\
5.4 & \leq \operatorname{Pr} \leq 6.8, \\
2.8 \times 10^{4} \leq G r & \leq 3.2 \times 10^{4}, \\
6.1 \times 10^{4} & \leq G r^{*} \leq 3.7 \times 10^{5}\end{aligned}$} \\
\hline & $(25)$ & 179 & 53 & 75 & 93 & 7.3 & \\
\hline $\begin{array}{l}\text { Quasi-turbulent } \\
\text { and turbulent }\end{array}$ & (26) & 653 & 99.8 & 100 & 100 & 1.4 & $\begin{aligned} 2804 & \leq R e \leq 9787, \\
5.5 & \leq P r \leq 6.9, \\
8.9 \times 10^{2} & \leq G r \leq 1.4 \times 10^{4}, \\
5.9 \times 10^{4} \leq G r^{*} & \leq 3.6 \times 10^{5}\end{aligned}$ \\
\hline \multirow{2}{*}{$\begin{array}{l}\text { Laminar, } \\
\text { transitional, } \\
\text { quasi-turbulent } \\
\text { and turbulent }\end{array}$} & $\begin{array}{c}G r: \\
(27)\end{array}$ & 1329 & 74 & 91 & 97 & 4.5 & \multirow{2}{*}{$\begin{aligned} & 512 \leq \operatorname{Re} \leq 9787, \\
& 3.8 \leq \operatorname{Pr} \leq 6.9, \\
& 8.9 \times 10^{2} \leq G r \leq 7.8 \times 10^{4}, \\
& 5.9 \times 10^{4} \leq G r^{*} \leq 9.8 \times 10^{5}\end{aligned}$} \\
\hline & $\begin{array}{l}G r^{*}: \\
(27)\end{array}$ & 1329 & 77 & 91 & 96 & 4.4 & \\
\hline
\end{tabular}

From this table it follows that the laminar friction factor correlation was able to predict approximately all the data within $5 \%$, while a single correlation for the transitional, quasi- 
turbulent and turbulent flow regimes, was able to predict almost all the data (97\%) within 10\%. The average Nusselt number correlations were able to predict almost all the laminar, transitional, and quasi-turbulent and turbulent data within 10\%, 20\%, and 5\%, respectively. Furthermore, the combined correlations, in terms of both the Grashof number and modified Grashof number, that can be used to calculate the Nusselt numbers in all the flow regimes were able to predict $91 \%$ of the data within $10 \%$.

\section{Conclusions}

Up to now, no experimental work has been done specifically focussing on the relationship between the pressure drop and heat transfer characteristics of developing flow in the transitional flow regime. The purpose of this study was therefore to experimentally investigate the pressure drop and heat transfer characteristics of developing and fully developed flow in smooth tubes in the laminar, transitional, quasi-turbulent and turbulent flow regimes. The Reynolds number was varied between 700 and 10000 to ensure that the transitional and quasi-turbulent flow regimes, as well as sufficient parts of the laminar and turbulent flow regimes, were covered. It was found that the boundaries of the different flow regimes were the same for pressure drop and heat transfer, and that a direct relationship between pressure drop and heat transfer existed in the transitional flow regime as well. In the laminar flow regime, the relationship between pressure drop and heat transfer was a function of Grashof number (thus free convection effects), while it was a function of Reynolds number in the other three flow regimes. Correlations to predict the average friction factors as a function of average Nusselt number, as well as correlations to predict the average Nusselt number, for developing and fully developed flow in all flow regimes, were also developed.

\section{Acknowledgements}

The funding obtained in South Africa from the NRF, Stellenbosch University/ University of Pretoria Solar Hub, CSIR, EEDSM Hub, RDP and NAC is acknowledged and duly appreciated. This work was produced as part of a $\mathrm{PhD}$ in the Department of Mechanical and Aeronautical Engineering at the University of Pretoria by the first author, under the supervision of the second author. 


\section{References}

[1] J.P. Meyer, M. Everts, Single-phase mixed convection of developing and fully developed flow in smooth horizontal circular tubes in the laminar and transitional flow regimes, Int. J. Heat Mass Transf., (2017), Manuscript nr: HMT_2017_2231, submitted on 7 June 2017.

[2] B.S. Gill, Relationship between pressure drop and heat transfer coefficient, Hydrocarbon Processing, 79(8) (2000).

[3] Y.A. Cengel, Heat and Mass Transfer: A Practical Approach, 3rd ed., McGraw-Hill, Singapore, 2006.

[4] N.T. Obot, Smooth tube friction and heat transfer in laminar and transitional flow, International Communications in Heat and Mass Transfer, 19(3) (1992) 299-310.

[5] R. Allen, E. Eckert, Friction and heat-transfer measurements to turbulent pipe flow of water $(\operatorname{Pr}=7$ and 8$)$ at uniform wall heat flux, Journal of Heat Transfer, 86(3) (1964) 301310.

[6] F. Durst, S. Ray, B. Ünsal, O.A. Bayoumi, The development lengths of laminar pipe and channel flows, J Fluids Eng Trans ASME, 127(6) (2005) 1154-1160.

[7] H.K. Tam, L.M. Tam, A.J. Ghajar, Effect of inlet geometries and heating on the entrance and fully-developed friction factors in the laminar and transition regions of a horizontal tube, Exp. Therm. Fluid Sci., 44 (2013) 680-696.

[8] J.A. Olivier, J.P. Meyer, Single-phase heat transfer and pressure drop of the cooling of water inside smooth tubes for transitional flow with different inlet geometries (RP-1280), HVAC R Res, 16(4) (2010) 471-496.

[9] J.P. Meyer, Heat transfer in tubes in the transitional flow regime, in: 15th International Heat Transfer Conference, Kyoto, Japan, 2014.

[10] L.M. Tam, Transitional heat transfer in plain horizontal tubes, Heat Transfer Eng, 27(5) (2006) 23-38.

[11] A.J. Ghajar, L.M. Tam, Laminar-transition-turbulent forced and mixed convective heat transfer correlations for pipe flows with different inlet configurations, in: Winter Annual Meeting of the American Society of Mechanical Engineers, Publ by ASME, New York, United States, 1991, pp. 15-23.

[12] A.J. Ghajar, K.F. Madon, Pressure drop measurements in the transition region for a circular tube with three different inlet configurations, Exp. Therm. Fluid Sci., 5(1) (1992) 129-135.

[13] A.J. Ghajar, L.M. Tam, Heat transfer measurements and correlations in the transition region for a circular tube with three different inlet configurations, Exp. Therm. Fluid Sci., 8(1) (1994) 79-90.

[14] A.J. Ghajar, L.M. Tam, Flow regime map for a horizontal pipe with uniform wall heat flux and three inlet configurations, Exp. Therm. Fluid Sci., 10(3) (1995) 287-297.

[15] L.M. Tam, A.J. Ghajar, Effect of Inlet Geometry and Heating on the Fully Developed Friction Factor in the Transition Region of a Horizontal Tube, Exp. Therm. Fluid Sci., 15(1) (1997) 52-64.

[16] L.M. Tam, A.J. Ghajar, The unusual behavior of local heat transfer coefficient in a circular tube with a bell-mouth inlet, Exp. Therm. Fluid Sci., 16(3) (1998) 187-194.

[17] A.J. Ghajar, C.C. Tang, W.L. Cook, Experimental investigation of friction factor in the transition region for water flow in minitubes and microtubes, Heat Transfer Eng, 31(8) (2010) 646-657.

[18] H.K. Tam, L.M. Tam, A.J. Ghajar, S.C. Tam, T. Zhang, Experimental investigation of heat transfer, friction factor, and optimal fin geometries for the internally microfin tubes in the transition and turbulent regions, J. Enhanced Heat Transf., 19(5) (2012) 457-476. 
[19] L.M. Tam, H.K. Tam, A.J. Ghajar, W.S. Ng, C.K. Wu, The effect of inner surface roughness and heating on friction factor in horizontal mini-tubes, in: 15th International Heat Transfer Conference, Kyoto, Japan, 2014.

[20] J.P. Meyer, J.A. Olivier, Transitional flow inside enhanced tubes for fully developed and developing flow with different types of inlet disturbances: Part II-heat transfer, Int. J. Heat Mass Transf., 54(7-8) (2011) 1598-1607.

[21] J.P. Meyer, J.A. Olivier, Transitional flow inside enhanced tubes for fully developed and developing flow with different types of inlet disturbances: Part I - Adiabatic pressure drops, Int. J. Heat Mass Transf., 54(7-8) (2011) 1587-1597.

[22] J.P. Meyer, J.A. Olivier, Heat transfer and pressure drop characteristics of smooth horizontal tubes in the transitional flow regime, Heat Transfer Eng, 35(14-15) (2014) 12461253.

[23] J.P. Meyer, T.J. McKrell, K. Grote, The influence of multi-walled carbon nanotubes on single-phase heat transfer and pressure drop characteristics in the transitional flow regime of smooth tubes, Int. J. Heat Mass Transf., 58(1-2) (2013) 597-609.

[24] J. Dirker, J.P. Meyer, D.V. Garach, Inlet flow effects in micro-channels in the laminar and transitional regimes on single-phase heat transfer coefficients and friction factors, Int. J. Heat Mass Transf., 77(0) (2014) 612-626.

[25] D.D. Ndenguma, J. Dirker, J.P. Meyer, Transitional flow regime heat transfer and pressure drop in an annulus with non-uniform wall temperatures, Int. J. Heat Mass Transf., 108 (2017) 2239-2252.

[26] J.P. Meyer, S.M. Abolarin, Heat transfer and pressure drop in the transitional flow regime for a smooth circular tube with twisted tape inserts and a square-edge inlet, Int. J. Heat Mass Transf., 117 (2018) 11-29.

[27] D. Taler, A new heat transfer correlation for transition and turbulent fluid flow in tubes, Int. J. Therm. Sci., 108 (2016) 108-122.

[28] D. Bertsche, P. Knipper, T. Wetzel, Experimental investigation on heat transfer in laminar, transitional nd turbulent circular pipe flow, Int. J. Heat Mass Transf., 95 (2016) 1008-1018.

[29] V. Gnielinski, New equations for heat and mass-transfer in turbulent pipe and channel flow, International Chemical Engineering, 16(2) (1976) 359-368.

[30] S.W. Churchill, Comprehensive correlating equations for heat, mass and momentum transfer in fully developed flow in tubes, Industrial Engineering Chemistry Fundamentals, 16(1) (1977) 109-116.

[31] W. Yu-ting, L. Bin, M. Chong-fang, G. Hang, Convective heat transfer in the laminarturbulent transition region with molten salt in a circular tube, Exp. Therm. Fluid Sci., 33(7) (2009) 1128-1132.

[32] J. Lu, S. He, J. Liang, J. Ding, J. Yang, Convective heat transfer in the laminar-turbulent transition region of molten salt in annular passage, Exp. Therm. Fluid Sci., 51 (2013) 71-76.

[33] V. Gnielinski, On heat transfer in tubes, Int. J. Heat Mass Transf., 63 (2013) 134-140.

[34] M. Everts, J.P. Meyer, Heat transfer of developing and fully developed flow in smooth horizontal tubes in the transitional flow regime, Int. J. Heat Mass Transf., (2017), Manuscript nr: HMT_2017_2232, submitted on 7 June 2017.

[35] J.P. Abraham, E.M. Sparrow, W.J. Minkowycz, Internal-flow Nusselt numbers for the low-Reynolds-number end of the laminar-to-turbulent transition regime, Int. J. Heat Mass Transf., 54(1-3) (2011) 584-588.

[36] M. Everts, J.P. Meyer, Flow regime maps for smooth horizontal tubes at a constant heat flux, Int. J. Heat Mass Transf., (2017), Manuscript nr: HMT_2017_2234, submitted on 7 June 2017. 
[37] M. Everts, Single-phase mixed convection of developing and fully developed flow in smooth horizontal circular tubes in the laminar, transitional, quasi-turbulent and turbulent flow regimes, $\mathrm{PhD}$ thesis, University of Pretoria, Pretoria, 2017 (under examination).

[38] L.M. Tam, A.J. Ghajar, H.K. Tam, S.C. Tam, Development of a flow regime map for a horizontal pipe with the multi-classification Support Vector Machines, in: 2008 Proceedings of the ASME Summer Heat Transfer Conference, HT 2008, 2009, pp. 537-547.

[39] H.K. Tam, L.M. Tam, A.J. Ghajar, C.W. Cheong, Development of a unified flow regime map for a horizontal pipe with the support vector machines, in: AIP Conference Proceedings, 2010, pp. 608-613.

[40] R. Rayle, Influence of orifice geometry on static pressure measurements, American Society of Mechanical Engineers, 1959.

[41] A. Bakker, R.D. LaRoche, E.M. Marshall, Laminar flow in static mixers with helical elements, in: The Online CFM Book, 2000.

[42] C.O. Popiel, J. Wojtkowiak, Simple formulas for thermophysical properties of liquid water for heat transfer calculations [from $\mathrm{O}^{\circ} \mathrm{C}$ to $150^{\circ} \mathrm{C}$ ], Heat Transfer Eng, 19(3) (1998) 87-101.

[43] P.F. Dunn, Measurement and Data Analysis for Engineering and Science, 2nd ed., CRC Press, United States of America, 2010.

[44] R.K. Shah, A.L. London, Laminar Flow Forced Convection in Ducts, Academic Press, New York, 1978.

[45] S.M. Morcos, A.E. Bergles, Experimental investigation of combined forced and free laminar convection in horizontal tubes, Journal of Heat Transfer, 97(2) (1975) 212-219.

[46] F.M. White, Fluid Mechanics, 6th ed., McGraw-Hill, Singapore, 2009.

[47] X. Fang, Y. Xu, Z. Zhou, New correlations of single-phase friction factor for turbulent pipe flow and evaluation of existing single-phase friction factor correlations, Nuclear Engineering and Design, 241 (2011) 897-902.

[48] H.L. Langhaar, Steady flow in the transition length of a straight tube, Journal of Applied Mechanics, 9 (1942) A-55-A-58.

[49] B. Metais, E. Eckert, Forced, mixed, and free convection regimes, Journal of Heat Transfer, 86(2) (1964) 295-296.

[50] M. Everts, Heat transfer and pressure drop of developing flow in smooth tubes in the transitional flow regime, Masters dissertation, University of Pretoria, Pretoria, 2014.

[51] V. Gnielinski, Ein neues Berechnungsverfahren für die Wärmeübertragung im Übergangsbereich zwischen laminarer und turbulenter Rohrströmung, Forschung im Ingenieurwesen, 61(9) (1995) 240-248.

[52] S.W. Churchill, R. Usagi, A general expression for the correlation of rates of transfer and other phenomena, AIChE Journal, 18(6) (1972) 1121-1128. 